\title{
Multi-objective optimisation of vehicle bodies made of FRP sandwich structures
}

\author{
Marian N. VELEA ${ }^{\mathrm{a}, 1}$ \\ ${ }^{a}$ Department of Aeronautical and Vehicle Engineering, Royal Institute of Technology (KTH), \\ SE-100 44 Stockholm, Sweden \\ velea@kth.se

\section{Per WENNHAGE ${ }^{\mathrm{b}}$} \\ ${ }^{b}$ Department of Aeronautical and Vehicle Engineering, Royal Institute of Technology (KTH), \\ SE-100 44 Stockholm, Sweden \\ wennhage@kth.se

\section{Dan ZENKERT ${ }^{\mathrm{c}}$} \\ ${ }^{c}$ Department of Aeronautical and Vehicle Engineering, Royal Institute of Technology (KTH), \\ SE-100 44 Stockholm, Sweden \\ danz@kth.se
}

\section{Corresponding author:}

Marian N. VELEA

Department of Aeronautical and Vehicle Engineering, Royal Institute of Technology (KTH), SE-100 44 Stockholm, Sweden

E-mail: velea@kth.se

Phone: +40723676387

\footnotetext{
${ }^{1}$ Permanent address: Department of Mechanical Engineering, Transilvania University of Braşov, 1 Politehnicii Street, 500024, Braşov, Romania, marian.velea@unitbv.ro
} 


\begin{abstract}
An optimisation methodology is developed and applied on a FRP sandwich body of an electric vehicle - ZBee, where single-objective and multi-objective optimisation studies are performed stepwise using a commercially available software package. The single-objective optimisation allows the identification of the load paths within the composite body, according to the loading conditions previously defined. Within the multi-objective optimisation, the optimum thickness and distribution for each of the layers that form the composite body are searched within the design space so as to obtain the best performance with respect to weight, material cost, global and local stiffness. Strength requirements are also considered as constraints within the optimisation. A conflict situation appears when several objectives are considered within the optimisation, meaning that an increased performance in one objective may often lead to a decreased performance for the others. Therefore, a trade-off between objectives is needed. The interpretation of results is partially made by using trade-off plots, the so-called Pareto frontiers. A method for the overall selection of the most beneficial solutions is proposed and applied in order to choose between the best obtained solutions according to the importance of the objectives.
\end{abstract}

Keywords: Composite structures, FRP sandwich, Multi-objective optimisation.

\title{
1. Introduction
}

An extensive interest within vehicles industries to develop and make use of lightweight composite materials and structures has been generated by the need of reducing energy consumption within the vehicles' use-phase. Clear benefits of using composites especially with respect to weight reduction have been reported within aeronautical, rail, naval and automotive industries. Especially for electric vehicles, the use of fibre reinforced polymers (FRP) represents a salient approach to increase their range. Such a demonstration is given by the ZBee vehicle which represents the materialized vision of a Swedish company - Clean Motion $\mathrm{AB}$ - regarding energy efficient electric vehicles. This urban vehicle, classified as scooter according to EU regulations, has been designed for short distance transportation of up to three people and smaller goods. Figure 1 shows the $2^{\text {nd }}$ generation of the ZBee vehicle. The body in white was entirely made of FRP composites. Certain sections within the body were made of FRP sandwich structure for an increased bending stiffness, having PVC foams and polymer honeycombs as cores. The composite body was made of 9 parts which were adhesively bonded together to form a whole.

A new generation of the ZBee - the $3^{\text {rd }}$ generation - , Figure 2, aims at an increased performance in terms of weight, material costs, local and global stiffness behaviour compared to the $2^{\text {nd }}$ generation.

Space for even more increased performance exists due to the fact that overall properties of FRP composites may be tailored to satisfy specific design requirements by changing the values of the constituents' specific parameters [1]. This goal can be attained if appropriate advanced optimisation tools are used.

An optimisation problem is most often formulated when trying to improve the vehicles' performance by weight reduction. An optimal solution of the objective function (e.g. mass) is 
searched within a design space defined by the upper and lower limits of the design variables (e.g. materials' properties) and by certain imposed constraints (e.g. required stiffness, strength etc.) [2].

However, lowering the weight of a vehicle will most often imply a reduction of other performance criteria such as the stiffness and strength properties, material cost or the safety performance. Therefore, there are cases where several objectives need to be defined and considered within the optimisation procedure in which case a conflict situation appears between objectives, meaning that an increased performance in one objective leads to a decreased performance for the others [3]. Several complex optimisation techniques and algorithms have been proposed for solving such multi-objective problems [1, 4-9].

The weighted sum approach has been used as an attempt to simplify the problem complexity of finding solutions within multi-objective optimisation problems, where all the objectives functions are summed into a single objective function, giving weight penalties for each of them [1]. Then, a solution may be obtained by running one of the many existing singleobjective optimisation algorithms. The main drawback regarding the weighted sum method is the quantification of weight penalties because the results are strongly dependent on them [10], although methods for dealing with this issue have been studied and proposed [11].

Therefore, in order to obtain a large spectrum of solutions, dedicated multi-objective optimisation algorithms remain here of interest $[12,13]$. One of the most spread algorithms within the current available commercial FE packages is the so-called MOGA (Multiobjective Optimisation Genetic Algorithm) [14]. Instead of providing one single solution, MOGA produces a set of solutions by searching within the design space for a set of Pareto optimal solutions [15]. The interpretation of results in the case of a multi-objective optimisation study is partially made with the help of the trade-off curves, the so-called Pareto frontiers [16]. The obtained Pareto frontiers only indicate the set of solutions that gives the best compromise between objectives, but there is a further need for choosing one single solution from the set. This can be done either by intuition or by reformulating the objectives as constraints, except one of them, or by using a composite objective function [3].

This article firstly addresses the problem of optimizing the FRP sandwich body of the new ZBee with respect to weight, stiffness, strength and material costs. Secondly, a selection method of the most beneficial design solutions is developed and applied in order to deal with the difficulties of interpreting the multi-objective optimisation results generated by MOGA.

All the values of the results characterizing the performance of the $3^{\text {rd }}$ generation are normalized to the ones that characterize the $2^{\text {nd }}$ generation, in order to evaluate the gained improvements.

\section{Numerical model}

All the analyses and optimisation studies have been performed within the Hyperworks 11 software package. Hypermesh facilities were used to simplify the geometry, to generate the mesh, to define material properties and to assign load cases. Optistruct solver was used for FE analyses and single-objective optimisation studies. Hyperstudy and RADIOSS solver was used for multi-objective optimisation studies. 
The FE mesh is generated on the outer surface of the body parts. The target finite element size was set to $10 \mathrm{~mm}$. Quad and triangular shell elements were used to realize an initial automated mesh of the body parts.

The generated finite elements have been checked and refined where needed, according to the HyperMesh quality indexes default values [17]. The resulted mesh has 688638 degrees of freedom, Figure 3. The connection between body parts (i.e. the adhesive) has been modelled using rigid elements in order to simplify the model.

\subsection{Material properties}

The composite structures the body parts are made of are modelled in HyperMesh as laminates, each laminate being composed by several plies (layers). The material properties were thus defined individually for each of the layers within the software. Table 1 shows the types of layers that were used within the body structure of the ZBee-Generation 3 and their corresponding material characteristics. The acronyms GF-weave and GF-csm represent a bidirectional weave and glass fibre chopped strands mats respectively. SORIC represents a polymer honeycomb core material.

\subsection{Loading conditions}

Within the analysis and optimisation of the ZBee composite body there have been considered 6 loading conditions. The corresponding loads and constraints are illustrated in Figure 4.

\subsubsection{Global torsion}

This load case has the purpose to evaluate the torsion stiffness of the whole composite body. Figure 4(a) shows the considered boundary conditions, where node B has all the degrees of freedom retained. The torsion stiffness $K_{t}$ is thus determined using Equation (1), where $M_{x A}$ is the moment applied along $\mathrm{X}$-axis at point $\mathrm{A}$ and $\theta_{x A}$ represents the rotation measured around $\mathrm{X}$-axis at point $\mathrm{A}$.

$$
K_{t}=\frac{M_{x_{A}}}{\theta_{x_{A}}}\left[\frac{\mathrm{Nm}}{\mathrm{deg}}\right]
$$

\subsubsection{Global bending}

The bending stiffness $K_{b}$ of the composite body is determined using Equation (2), where $F_{z C}$ is the force applied along $\mathrm{Z}$-axis at point $\mathrm{C}$ and $\delta_{z C}$ represents the displacement measured along $\mathrm{Z}$-axis at point $\mathrm{C}$. The node $\mathrm{B}$ has all degrees of freedom retained while node $\mathrm{A}$ is allowed to slide along X-direction, Figure 4(b).

$$
K_{b}=\frac{F_{z_{C}}}{\delta_{z_{C}}} \quad\left[\frac{\mathrm{N}}{\mathrm{mm}}\right]
$$

\subsubsection{Front wheel brake}

This load case has been introduced in order to evaluate the local stiffness of the composite body around the front wheel, Figure 4(c). It is assumed that the vehicle is travelling on a 
downhill gradient of $15^{\circ}$ and only the front wheel is braking (worst case). Taking into consideration the legal requirements that the vehicle needs to stop with an average deceleration of $2.7 \mathrm{~m} / \mathrm{s}$, a braking force $F$ and a braking moment $M$ are determined and both are applied on point $\mathrm{B}$ (centre of the front wheel); the displacement of point $\mathrm{C}$ (the headstock top point) is then determined using Equation (3), where $\delta_{x}, \delta_{y}$ and $\delta_{z}$ represent the displacements of point $\mathrm{C}$ evaluated within the analyses along the three orthogonal axes.

$$
\delta=\sqrt{\delta_{x}^{2}+\delta_{y}^{2}+\delta_{z}^{2}}[\mathrm{~mm}]
$$

Within this load scenario, inertia relief is used to obtain the load equilibrium of the model [18]. Thus, the applied loads $F$ and $M$ are balanced by inertial accelerations that automatically provide forces distributed over the body in such a way that the sum of the applied forces is equal to zero. However, all the degrees of freedom of node A, Figure 4(c), are constrained in order to restrain the rigid body motion, but the reaction forces on this node are zero [17].

\subsubsection{Belt points forces}

Specific local stiffness at belt points is also required. Within this load case, static forces are applied at belt points and their displacements are evaluated and used as constraints within the optimisation study. The degrees of freedom are restrained for all the bottom nodes, Figure $4(d)$.

\subsubsection{Front impact}

For the homologation of the vehicle, several safety requirements need to be fulfilled and therefore equivalent load scenarios also need to be included within the simulations. Dynamic non-linear FE analyses are usually considered for investigating this type of crash scenarios [19] but these imply a high computational time, especially in the case of a multi-objective optimisation. For this reason, an equivalent static load case is here approximated, Figure 4(e), where a force $F$ is applied on the depended node $\mathrm{B}$ and distributed within interpolation constraint elements - RBE3 [17] on an estimated impact area from the composite body. The magnitude of the force $F$ equals $M \cdot 10 g$, where $M$ is the full vehicle mass and $g$ is the gravitational acceleration. The displacement of point B is then evaluated and used within the optimisation studies as a constraint or objective in the form of Equation (3).

As in the case of the Front wheel brake load case, the inertia relief is used here too for obtaining the load equilibrium of the model. The degrees of freedom of node A, Figure 4(e), are constrained in order to restrain the rigid body motion.

Although this is a roughly simplified way to simulate a front impact scenario, it is anyway expected that the applied static force will unveil the load paths by increasing the thickness of specific layers as required in order to satisfy the displacement constraint of point B. Other authors have used the same approach for single-objective topology optimisation [20].

\subsubsection{Curb strike}

This load case allows the effect of the load distributed within the composite body to be considered when the front wheel hits a curb. The force $F$, Figure 4(f), is calculated as $M \cdot 3 g$, where $M$ is the full vehicle mass and $g$ is the gravitational acceleration. It is assumed that the 
curb has a height of $100 \mathrm{~mm}$ and the wheel radius is $230 \mathrm{~mm}$. The force is then applied in the centre of the wheel represented by the point B, Figure 4(f), at an angle of $34^{\circ}$ from Ox axis, within the $\mathrm{xOy}$ plane, and it is transferred to the composite body by the interpolation constraint elements - RBE3 [17], that represent the fork.

The displacement of point $\mathrm{B}$ is evaluated and used within the optimisation studies as a constraint or objective in the form of Equation (3).

\section{Optimisation Methodology}

The proposed optimisation methodology consists of three main steps, Figure 5.

First, a single-objective free size optimisation is performed on the composite body modelled as described at paragraph 2. Within the second step, the area covered by each layer is redefined according to the obtained distribution of thicknesses from the free size optimisation results. The last step consists of performing a multi-objective size optimisation to the redefined patches.

A detailed description of these three steps is given further on.

\subsection{Free size optimisation}

When referring to composite laminates, the mathematical formulation of the single-objective free size optimisation problem may be described as it follows (adapted from [21]):

Minimize $\quad f(x)=f\left(x_{11}, \ldots, x_{i j}\right)$

Subject to $\quad x_{i j}^{L} \leq x_{i j} \leq x_{i j}^{U}, \quad i=1, \ldots, N l ; j=1, \ldots, N e$

where:

$$
g_{k}(x)-g_{k}^{U} \leq 0, \quad k=1, \ldots, m \text {; }
$$

- $f(x)$ is the objective function

- $\quad x_{i j}$ represents the thickness of the $i^{\text {th }}$ layer of the $j^{\text {th }}$ finite element

- $\quad g_{k}(x)$ and $g_{k}^{U}$ are the $k^{\text {th }}$ constraint response and its upper bound

- $\quad \mathrm{Nl}$ and $\mathrm{Ne}$ represent the number of layers and the number of elements

- $\quad m$ is the number of constraints

The goal at this stage is to identify the load paths through the composite body for the given loading conditions. The initial structure of the parts is considered to be made of six layers all over the body, according to the section illustrated in Figure 6.

The initial thicknesses of the GF-weave and GF-csm layers, Table 2, have been predicted using Equation (4).

$$
h=\frac{W_{f}}{\rho_{f}}+\frac{W_{m}}{\rho_{m}}
$$

where:

$W_{f}$ and $W_{m}$ represent the weight of the fibres and of the matrix per unit area; $W_{f}$ is given in Table 2. 
$W_{m}$ is calculated for each as $W_{m}=\left(W_{f} / W_{f}\right)-W_{f}$, where $W_{f}=\rho_{f} V_{f} /\left(\rho_{f} V_{f}+\rho_{m} V_{m}\right), V_{f}$ represents the fibre volume fraction and it is equal to 0.4 for GF-weave and 0.2 for GF-csm. The matrix volume fraction $V_{m}$ is equal to $1-V_{f}$.

- $\quad \rho_{f}$ and $\rho_{m}$ are the densities of the glass fibres and of the polyester matrix, and they are equal to $2520 \mathrm{Kg} / \mathrm{m}^{3}$ and $1160 \mathrm{Kg} / \mathrm{m}^{3}$ respectively, [22].

\subsubsection{Design variables}

Within the free size optimisation, the thickness value of the layers shown in Figure 6 is allowed to vary freely within a predefined interval for each finite element. These thicknesses represent the design variables and their upper and lower limits are shown in Table 3. The thickness of the Gelcoat layer is kept constant.

\subsubsection{Constraints}

The imposed design constraints within the free size optimisation may be interpreted as performance targets that should be met, for each of the considered load cases. The applied constraints are described in Table 4.

The values for the objective functions $K_{t 3}$ and $K_{b 3}$ are constrained to be at least equal to two times the corresponding values for the $2^{\text {nd }}$ generation in order to force the PUR layer to grow in a more realistic shape instead of a scattered distribution.

\subsubsection{Objective}

The single-objective is to minimize the mass of the composite body by varying the defined design variables, Table 3, while satisfying the imposed design constraints, Table 4.

\subsubsection{Results}

The contour plot representing the thickness distribution of the PUR layer, Figure 7, shows a thickness distribution up to $60 \mathrm{~mm}$ around the bucket region, although the upper limit of the corresponding design variable has been set to $30 \mathrm{~mm}$, Table 3 . This happens because a Tjoint exists around the bucket and therefore the model implies two layers of PUR foam that are concurring within that region.

A feasible solution has been reached within this optimisation step, where the mass has been decreased by $29.9 \%$ compared to the $2^{\text {nd }}$ generation, at the same time by satisfying all the constraints defined in Table 4.

Although a theoretical feasible solution was obtained within the free-size optimisation, the resulted thickness distribution of each layer within the composite body is hard to reproduce in reality, especially the layer that represents the core, Figure 7. For this reason, the interpretation of patches has been considered as a next step.

\subsection{Interpretation of patches}

The area covered by each layer is interpreted following the free size optimisation results, and redefined in order to reach a shape that is possible to manufacture. This step requires the assistance of experts on manufacturing technologies of composites.

Figure 8(a) shows the distribution of the PUR foam within the composite body (gray areas) as it was interpreted based on the information provided by the free size optimisation results, Figure 7 , and by the recommendations coming from manufacturing experts. One of the 
benefits of using PUR as a core within the composite body is that it may be extruded by using moulds into complex shapes that can better follow the load paths indicated by the analysis. However, there are regions within the composite body where higher local bending stiffness is required; PVC foam has higher stiffness properties comparing to PUR foam, Table 1, and therefore it may provide a better behaviour. Still, milling the PVC foam into complex shapes may be an expensive process and thus this solution is acceptable only on relatively flat regions within the body. Such areas are shown in Figure 8(b): the backrest and the bottom area of the floor. The backrest part allows the transfer of loads between floor, sides, seat and roof and therefore its contribution to the global behaviour of the body is important. Also, the bottom area of the floor requires higher bending stiffness due to the loads coming from the road within the connection of the wheels to the body, and from the seat and the backrest.

There are regions within the model where no PUR was required following the considered loading conditions, Figure 7. However, in order to avoid stability issues [23], a 3mm SORIC honeycomb [24] is required to be placed where no PUR is located - within the roof and the sides, Figure 8(c).

Reinforcement patches consisting of glass fibre weaves have been considered within the floor region where the front wheel fork is connected to composite body, Figure 8(d).

\subsection{Size optimisation}

The size optimisation is performed by considering multiple objectives. In the context of composite laminates, the mathematical description of the multi-objective size optimisation problem may be formulated as it follows:

$$
\begin{array}{ll}
\text { Minimize } & F\left(x_{i j}\right)=\left[f_{1}\left(x_{i j}\right), f_{2}\left(x_{i j}\right), \ldots, f_{n}\left(x_{i j}\right)\right]^{T} \\
\text { Subject to } & x_{i j}^{L} \leq x_{i j} \leq x_{i j}^{U}, \quad i=1, \ldots, N l ; j=1, \ldots, N s \\
& g_{k}(x)-g_{k}^{U} \leq 0, \quad k=1, \ldots, m ;
\end{array}
$$

where:

- $\quad n$ is the number of objective functions;

- $\quad x_{i j}$ represents a vector of design variables; it may be formed by thicknesses and fibre orientation angles for each of the $i^{\text {th }}$ layer placed within the $j^{\text {th }}$ set of elements

- $\quad g_{k}(x)$ and $g_{k}^{U}$ are the $k^{\text {th }}$ constraint response and its upper bound

- $\quad N l$ and $N s$ represent the number of layers and the number of the elements sets the composite body is divided in

- $\quad m$ is the number of constraints

Within the present study, a multi-objective genetic algorithm (MOGA) that is implemented in HyperStudy is used to perform the size optimisation by considering multiple objective functions.

\subsubsection{Objectives}

A number of 7 objectives functions have been defined within the size optimisation stage, Table 5.

The objective function representing the material cost is modelled according to Equation (5) and considering the assumptions made in Table 6. 


$$
C=\sum_{i=1}^{n} \sum_{j=1}^{m}\left(C_{k g} \times A_{i j} \times \rho_{i j} \times T_{i j}\right)
$$

where:

- $\quad \mathrm{n}$ - the number of body parts

- $\quad \mathrm{m}-$ the number of layers within body part

- $\mathrm{C}_{\mathrm{kg}}$ - material cost per $\mathrm{Kg}$

- $\quad A_{i j}$ - area covered by $j$ layer within $i$ part

- $\quad \rho_{i j}-$ material density of $j$ layer within $i$ part

- $\quad T_{i j}-$ thickness of $j$ layer within $i$ part

\subsubsection{Design variables}

The considered design variables represent the thicknesses of the layers redefined in step B (interpretation of patches) and they are shown in Table 7. Because the layers that form the composite laminates are considered to have equal in-plane properties, Table 1, the fibre orientation angle is not included in the optimisation.

According to the defined sections within the body and by considering the number of layers, Table 7, it resulted a total number of 42 variables.

\subsubsection{Constraints}

Three constraints were considered within this optimisation step, Table 8.

The values for the objective functions $K_{t 3}$ and $K_{b 3}$ are allowed within this optimisation step to decrease up to half the values of the $2^{\text {nd }}$ generation in order to increase the trade-off space with the conflicting objectives, by adding more solutions. Thus, low performance values for $K_{t 3}$ and $K_{b 3}$ will allow reaching high performance values for the conflicting objectives, as it will be shown further on.

Tsai-Hill criterion was used in order to predict failure in the composite body assuming equal values for compressive and tensile strength. However, Tsai-Wu failure criterion may be used when different behaviour in compression and tension must be taken into account [25].

Thus, according to Tsai-Hill failure criterion, a value below 1 for the failure index given by Equation (6) indicates that the stress is within the allowable limits [26]. However, within the optimisation, this failure index is constrained to have a value below or equal to 0.2. This constraint is applied on certain finite elements that were identified as critical within a single run analysis considering the layers shown in Figure 8 and their initial thickness value shown in Table 7.

$$
F=\frac{\sigma_{1}^{2}}{X^{2}}+\frac{\sigma_{1} \sigma_{2}}{X^{2}}+\frac{\sigma_{2}^{2}}{Y^{2}}+\frac{\tau_{12}^{2}}{S^{2}}
$$

where:

- $\sigma_{1}$ and $\sigma_{2}$ are the in-plane stresses along longitudinal and transverse direction,

- $\tau_{12}$ represents the shear stress,

- $X$ and $Y$ represent the allowable stress in longitudinal and transverse direction,

$-S$ is the allowable shear stress. 


\subsubsection{Results}

The obtained values for the objective functions from the multi-objective size optimisation are graphically presented from Figure 9 to Figure 14 and arranged in a tabular form within Table 9 , as normalized values to the ones characterizing the $2^{\text {nd }}$ generation of the ZBee; the Mass objective is plotted against all the other considered objectives. For the objectives to be minimized, improvements are observed if their normalized value is below 1 , while a value above 1 indicates improvements of the objectives to be maximized.

The plots shown, Figure 9 to Figure 14, are also divided into four regions (I - IV) in order to clearly show and classify the performance offered by each of the design solutions. The performance is increased for both of the objectives if the solution comes from region I or it is decreased for both of the objectives if the solution comes from region IV. Region II and III contain those solutions where only one of the objectives has an increased performance.

The trade-off between two objectives may be then realized by choosing the solution preferably from those placed within region I, Figure 9 to Figure 14, by identifying the Pareto front (red line), and by making the trade-off between the points that define the Pareto front, in terms of the objective importance. However, when it comes to multiple objectives, difficulties with using the Pareto front arise from the fact that the best compromise between two objectives does not necessarily represent the best one between some other two objectives. Therefore, an overall performance of the objectives is needed, that relates the contribution of each objective when searching the most beneficial overall solution. Such an overall performance function is adapted here from [3], where proportion factors are applied to relate the contribution of the objectives, Equation (7).

$$
P_{S}=\frac{\sum_{i=1}^{n} p_{i} \times \overline{O_{i}}-\sum_{j=1}^{m} p_{j} \times \overline{O_{j}}}{100}
$$

where:

- $\quad P_{s}$ represents the overall performance function;

- $\bar{O}_{l}$ represents the normalized value of the $i^{\text {th }}$ objective to be minimized $i=1, \ldots, \mathrm{n}$;

$\bar{O}_{\iota}=\xi\left(O_{i_{\text {max }}}-O_{i_{\text {min }}}\right)+O_{i_{\text {min }}}, \xi \in[0,1]$

- $\bar{O}_{\text {J }}$ represents the normalized value of the $j^{\text {th }}$ objective to be maximized, $j=1, \ldots, \mathrm{m}$;

$\bar{O}_{J}=\xi\left(O_{j_{\text {max }}}-O_{j_{\text {min }}}\right)+O_{j_{\text {min }}}, \xi \in[0,1]$

- $\quad p_{i}$ represents the proportion to which the value of the $i^{\text {th }}$ objective contributes to the overall performance function $P$, in percents;

- $\quad p_{j}$ represents the proportion to which the value of the $j^{\text {th }}$ objective contributes to the overall performance function $P$, in percents;

- $\quad \sum_{i=1}^{n} p_{i}+\sum_{j=1}^{m} p_{j}=100 \%$.

The minimum value of the overall performance function $P_{s}$ gives the best compromise between the considered objectives while taking into account the desired value for the proportions $p_{i}$ and $p_{j}$.

Table 9, correlated with the graphical representations shown within Figure 9 to Figure 14, shows a selection of eight possible solutions obtained by varying the proportion factor $p$ in 
such a way to give different contributions of the objective functions to the obtained design solution. Within Table 9, Obj columns show the resulted values of the objective functions, for each of the possible solutions.

The solutions denoted $S_{\text {local }}$ which are shown only within Figure 9 to Figure 14, are obtained by defining equal proportion factors (both having a value of 50\%) for each of the plotted objective functions, on each graph. This is a simple verification that the selection method used here gives the best compromise between two selected objectives.

Within the solution denoted S1, the contribution of the Mass objective function has a proportion of 25\%, the Material Cost 20\%, both Torsion Stiffness and Bending Stiffness objectives represent $20 \%$, while all the remain objectives only $5 \%$ each. This case shows a tied trade-off between objectives, where the Mass objective has the most important influence on the solution, followed by Material Cost, Torsion Stiffness and Bending Stiffness with equal importance. The solution $S 1$ gives improvements for all the objective functions except the one corresponding to the front impact load scenario, Figure 14. This can be further on finetuned as required by redefining the proportion factors $p$.

The negative sign on the proportion factor applied to Torsion Stiffness and Bending Stiffness indicates that these objectives are to be maximized. The minimum value obtained for the overall performance function $P_{s}$ is in this case equal to -0.010 , which allows further on the identification of the solution number that gives the best overall performance, Figure 15.

In the same manner, $S 2-S 8$ represent solutions where different proportion factors are defined, Table 9, in order to look for extreme dominated solutions and also to demonstrate the utility of the proposed selection method. Thus, $S 2$ represents Mass dominated solution ( $p$ $=94 \%) . S 3$ and $S 4$ represent Torsion Stiffness dominated solution $(p=-94 \%)$ and Bending Stiffness dominated solution $(p=-94 \%)$ respectively. As it was previously described, the negative sign indicates that the objective that dominates the solution needs to be maximized. Further on, $S 5-S 8$ are solutions dominated by objectives which are to be minimized, all of these objectives having the proportion factor $p$ equal to 94\%. The Failure Index constraint, Table 8 , has been found to be active for seldom design solutions; however, it was not active for the selected solutions $S 1-S 8$, Table 9.

In order to produce such kind of overall optimum solutions by using the herein proposed method there is a need to first define the proportion factors $p$. With other words, one should be able to answer the question: what is the proportion with which each objective should contribute to the chosen design solution?

Each design solution corresponds to a distinct set of values for the design variables (layers' thickness); within the optimisation, the design variables vary between the predefined limits. The obtained values of the design variables are shown within Figure 16 and Figure 17, for each of the selected solutions, $S 1-S 8$, for the Backrest and Roof sections. These plots represent sections within the composite parts, showing the thickness value for each of the layers. The symmetric distribution of the layers comes from the fact that symmetry constraints were considered within the optimisation problem definition.

Similar plots may be generated for each part and used for extracting the thickness that has to be used for each layer, for all body parts, within the manufacturing process. 


\section{Conclusions}

The composite body of a new electric vehicle - ZBee has been optimized with respect to weight, material costs, stiffness and strength, within an optimisation methodology that consists of three main steps. The second step of the described optimisation methodology (the identification of patches), implies knowledge input from manufacturing experts, for which reason a fully automated methodology could not be implemented here. Future research is required for dealing with this issue.

The proposed optimisation methodology allows generating multiple design solutions at its end, from which the most beneficial ones are searched by following the importance allocated for each of the objectives, using the so-called proportion factors.

\section{Acknowledgement}

This research has been conducted within the OptFRPBody project funded by Mistra Innovation - The foundation for Strategic Environmental Research, Sweden. The funding is gratefully acknowledged. The authors thank all the project partners for their collaboration.

\section{References}

1. Walker M, Smith RE. A technique for the multiobjective optimisation of laminated composite structures using genetic algorithms and finite element analysis. Composite Structures. 2003;62:123-8.

2. Harte AM, McNamara JF, Roddy ID. A multilevel approach to the optimisation of a composite light rail vehicle bodyshell. Composite Structures. 2004;63:447-53.

3. Ashby MF. Multi-objective Optimization in Material Design and Selection. Acta Materialia. 2000;48:359-69.

4. Marler RT, Arora JS. Survey of multi-objective optimization methods for engineering. Structural and Multidisciplinary Optimization. 2004;26:369-95.

5. Badalló P, Trias D, Marín L, Mayugo JA. A comparative study of genetic algorithms for the multi-objective optimization of composite stringers under compression loads. Composites Part B: Engineering. 2013;47:130-6.

6. Wang K, Kelly D, Dutton S. Multi-objective optimisation of composite aerospace structures. Composite Structures. 2002;57:141-8.

7. Pohlak M, Majak J, Karjust K, Küttner R. Multi-criteria optimization of large composite parts. Composite Structures. 2010;92:2146-52. 
8. Herranen H, Pabut O, Eerme M, Majak J, Pohlak M, Kers J, et al. Design and Testing of Sandwich Structures with Different Core Materials. Materials Science (Medziagotyra). 2012;18:45-50.

9. Kers J, Majak J, Goljandin D, Gregor A, Malmstein M, Vilsaar K. Extremes of apparent and tap densities of recovered GFRP filler materials. Composite Structures. 2010;92:2097101.

10. Kaufmann M, Zenkert D, Wennhage P. Integrated cost/weight optimization of aircraft structures. Structural and Multidisciplinary Optimization. 2010;41:325-34.

11. Marler RT, Arora J. The weighted sum method for multi-objective optimization: new insights. Structural and Multidisciplinary Optimization. 2010;41:853-62.

12. Lee DS, Morillo C, Bugeda G, Oller S, Onate E. Multilayered composite structure design optimisation using distributed/parallel multi-objective evolutionary algorithms. Composite Structures. 2012;94:1087-96.

13. Almeida FS, Awruch AM. Design optimization of composite laminated structures using genetic algorithms and finite element analysis. Composite Structures. 2009;88:443-54.

14. Fonseca CM, Fleming PJ. Genetic Algorithms for Multiobjective Optimization: Formulation, Discussion and Generalization. 5th Int Conf on Genetic Algorithms1993. p. 416-23.

15. Konak A, Coit DW, Smith AE. Multi-objective optimization using genetic algorithms: A tutorial. Reliability Engineering \& System Safety. 2006;91:992-1007.

16. Deb K. Multi-objective Optimisation Using Evolutionary Algorithms: An Introduction. In: Wang L, Ng AHC, Deb K, editors. Multi-objective Evolutionary Optimisation for Product Design and Manufacturing: Springer London; 2011. p. 3-34.

17. Altair. HyperWorks 11, Online Help and Documentation. 2012.

18. Christensen J, Bastien C, Blundell M, Gittens A, Tomlin O. Lightweight Hybrid Electrical Vehicle Structural Topology Optimisation Investigation Focusing on Crashworthiness. Int J Vehicle Structures \& Systems. 2011;3:113-22.

19. Duddeck F. Multidisciplinary optimization of car bodies. Structural and Multidisciplinary Optimization. 2008;35:375-89.

20. Cavazzuti M, Baldini A, Bertocchi E, Costi D, Torricelli E, Moruzzi P. High performance automotive chassis design: a topology optimization based approach. Structural and Multidisciplinary Optimization. 2011;44:45-56.

21. Zhou M. A Comprehensive Process for Composite Design Optimisation. The 6th Altair CAE Technology Conference2009. 
22. Åström BT. Manufacturing of Polymer Composites: Nelson Thornes Ltd, 2002.

23. Cervellera P, Zhou M, Schram U. Optimization driven design of shell structures under stiffness, strength and stability requirements. 6th World Congress of structural and Multidisciplinary Optimization. Rio de Janeiro2005.

24. LANTOR. Data Sheet - Lantor Soric XF Lantor BV2011.

25. Majak J, Hannus S. Orientational design of anisotropic materials using the HILL and TSAI-WU strength criteria. Mechanics of Composite Materials. 2003;39:509-20.

26. Groenwold AA, Haftka RT. Optimization with non-homogeneous failure criteria like Tsai-Wu for composite laminates. Struct Multidisc Optim. 2006;32:183-90. 
Figure Captions

Figure 1 The $2^{\text {nd }}$ generation of ZBee vehicle

Figure 2 The $3^{\text {rd }}$ generation of ZBee vehicle - new composite body design

Figure 3 Meshed body

Figure 4 The applied loads and constraints

Figure 5 Optimisation methodology applied on the composite body

Figure 6 Section within the composite body structure

Figure 7 Thickness distribution of the PUR foam layer

Figure 8 Interpretation of the layers' distribution within the composite body following the free size results: (a) PUR foam; (b) PVC foam ; (c) SORIC honeycomb ; (d) GF weave reinforcement.

Figure 9 Mass vs. Torsion Stiffness

Figure 10 Mass vs. Bending Stiffness

Figure 11 Mass vs. Material Cost

Figure 12 Mass vs. Displacement of point C from Figure 4(c)

Figure 13 Mass vs. Displacement of point B from Figure 4(f)

Figure 14 Mass vs. Displacement of point B from Figure 4(e)

Figure 15 The complete set of solutions vs. Overall performance function $P_{s}$ obtained within S1

Figure 16 Values of the layers' thicknesses obtained for the Backrest body part, for the selected design solutions

Figure 17 Values of the layers' thicknesses obtained for the Roof body part, for the selected design solutions 
Table 1 The materials properties used within the optimisation studies

\begin{tabular}{ccccccc}
\hline \multirow{2}{*}{$\begin{array}{c}\text { Material } \\
\text { Type }\end{array}$} & \multicolumn{5}{c}{ Material characteristics } \\
\cline { 2 - 6 } & $\boldsymbol{E}_{\boldsymbol{l}}=\boldsymbol{E}_{\boldsymbol{2}}[\mathbf{M P a}]$ & $\boldsymbol{G}_{\boldsymbol{l} 2}[\mathbf{M P a}]$ & $\boldsymbol{\rho}\left[\mathbf{K g} / \mathbf{m}^{3}\right]$ & $\boldsymbol{X}_{\boldsymbol{t}}=\boldsymbol{X}_{\boldsymbol{c}}[\mathbf{M P a}]$ & $\boldsymbol{Y}_{\boldsymbol{t}}=\boldsymbol{Y}_{\boldsymbol{c}}[\mathbf{M P a}]$ & $\boldsymbol{S}[\mathbf{M P a}]$ \\
\hline GF-weave & 16740 & 2237 & 1704 & 241 & 241 & 7 \\
GF-csm & 8462 & 1712 & 1432 & 129 & 129 & 9 \\
PUR foam & 55 & 21 & 150 & 1.8 & 1.8 & 1.18 \\
PVC foam & 130 & 35 & 100 & 2 & 2 & 1.6 \\
SORIC & 800 & 35 & 1160 & 4 & 4 & 3 \\
Gelcoat & 3800 & 1387 & 1200 & - & - & - \\
\hline
\end{tabular}


Table 2 Initial thickness and layers' distribution within the composite body

\begin{tabular}{llcc}
\hline Layer Type & Placement & $\boldsymbol{W}_{\boldsymbol{f}}\left[\mathbf{g} / \mathbf{m}^{\mathbf{2}}\right]$ & Initial thickness $[\mathbf{m m}]$ \\
\hline Gelcoat & complete layer & - & 0.600 \\
outer GF-csm & complete layer & 300 & 0.595 \\
outer GF-weave & complete layer & 600 & 0.595 \\
PUR & complete layer & - & 30 \\
inner GF-weave & complete layer & 600 & 0.595 \\
inner GF-csm & complete layer & 300 & 0.595 \\
\hline
\end{tabular}


Table 3

Table 3 Design variables within the free size optimisation step

\begin{tabular}{lcc}
\hline \multirow{2}{*}{ Layer } & \multicolumn{2}{c}{ Thickness [mm] } \\
\cline { 2 - 3 } & lower limit & upper limit \\
\hline outer GF-csm & 0.2 & 1.2 \\
outer GF-weave & 0 & 1.2 \\
PUR & 0 & 30 \\
inner GF-weave & 0 & 1.2 \\
inner GF-csm & 0.2 & 1.2 \\
\hline
\end{tabular}


Table 4 Constraints applied within the free size optimisation

\begin{tabular}{|c|c|c|}
\hline Load case & Constraint & Description \\
\hline $\begin{array}{l}\text { Torsion } \\
\text { stiffness }\end{array}$ & $K_{t 3} \geq 2 K_{t 2}$ & $\begin{array}{l}\text { Torsion stiffness of the } 3^{\text {rd }} \text { generation, Equation (1), should be at } \\
\text { least equal to two times the one of the } 2^{\text {nd }} \text { generation. }\end{array}$ \\
\hline $\begin{array}{l}\text { Bending } \\
\text { stiffness }\end{array}$ & $K_{b 3} \geq 2 K_{b 2}$ & $\begin{array}{l}\left.\text { Bending stiffness of the } 3^{\text {rd }} \text { generation, Equation ( } 2\right) \text {, should be at } \\
\text { least equal to two times the one of the } 2^{\text {nd }} \text { generation. }\end{array}$ \\
\hline $\begin{array}{l}\text { Front wheel } \\
\text { brake }\end{array}$ & $\delta_{C 3} \leq \delta_{C 2}$ & $\begin{array}{l}\text { Displacement of point } \mathrm{C} \text {, Figure } 4(\mathrm{c}) \text { of the } 3^{\text {rd }} \text { generation should } \\
\text { be less than or equal to the one of the } 2^{\text {nd }} \text { generation. }\end{array}$ \\
\hline $\begin{array}{l}\text { Belt points } \\
\text { stiffness }\end{array}$ & $\delta_{\text {belt_points_ } 3} \leq \delta_{\text {belt_points_2 }}$ & $\begin{array}{l}\text { Displacements of belt points, Figure } 4(\mathrm{~d}) \text { on the } 3^{\text {rd }} \text { generation } \\
\text { should be less than or equal to the ones of the } 2^{\text {nd }} \text { generation. }\end{array}$ \\
\hline Front impact & $\delta_{B 3} \leq \delta_{B 2}$ & $\begin{array}{l}\text { Displacement of point } \mathrm{B} \text {, Figure } 4(\mathrm{e}) \text { of the } 3^{\text {rd }} \text { generation should } \\
\text { be less than or equal to the one of the } 2^{\text {nd }} \text { generation. }\end{array}$ \\
\hline Curb strike & $\delta_{B 3} \leq \delta_{B 2}$ & $\begin{array}{l}\text { Displacement of point } \mathrm{B} \text {, Figure } 4(\mathrm{f}) \text { of the } 3^{\text {rd }} \text { generation should } \\
\text { be less than or equal to the one of the } 2^{\text {nd }} \text { generation. }\end{array}$ \\
\hline
\end{tabular}


Table 5 Objective functions defined within the size optimisation

\begin{tabular}{lll}
\hline Objective & Function & Description \\
\hline minimize & Mass of the composite body & Evaluated within the simulation \\
minimize & Material Cost & Defined by Equation (5) \\
maximize & Torsion Stiffness & Defined by Equation (1) \\
maximize & Bending Stiffness & Defined by Equation (2) \\
minimize & Headstock displacement & Defined by Equation (3) \\
minimize & Front impact penetration & Defined by Equation (3) \\
minimize & Front wheel centre displacement & Defined by Equation (3) \\
\hline
\end{tabular}


Table 6 Assumptions regarding the costs per $\mathrm{Kg}$ of the materials used within the composite body

\begin{tabular}{lc}
\hline Material & Cost per Kg [SEK/Kg] \\
\hline PVC & 500 \\
PUR & 200 \\
GF-weave-poly & 28 \\
GF-csm & 20 \\
SORIC & 100 \\
Gelcoat & 15 \\
\hline
\end{tabular}


Table 7 Design variables within the size optimisation step

\begin{tabular}{llccc}
\hline \multicolumn{1}{c}{ Layer } & Placement & \multicolumn{3}{c}{ Thickness [mm] } \\
\cline { 3 - 5 } outer GF-csm & complete layer & 0.2 & 0.595 & upper limit \\
outer GF-weave - reinforcement & see Figure 8(d) & 0 & 2.38 & 2.975 \\
outer GF-weave & complete layer & 0.2 & 0.595 & 1.2 \\
PUR & see Figure 8(a) & 0 & 30 & 40 \\
PVC & see Figure 8(b) & 0 & 15 & 20 \\
inner GF-weave & complete layer & 0.2 & 0.595 & 1.2 \\
inner GF-weave - reinforcement & see Figure 8(d) & 0 & 2.38 & 2.975 \\
inner GF-csm & complete layer & 0.2 & 0.595 & 1.2 \\
\hline
\end{tabular}


Table 8 Constraints applied within the multi-objective optimisation

\begin{tabular}{lll}
\hline Load case & Constraint & Description \\
$\begin{array}{l}\text { Torsion } \\
\text { stiffness }\end{array}$ & $K_{t 3} \geq 0.5 K_{t 2}$ & $\begin{array}{l}\text { Torsion stiffness of the } 3^{\text {rd }} \text { generation, Equation (1), should be at } \\
\text { least equal to half of the one of the } 2^{\text {nd }} \text { generation. } \\
\text { Bending } \\
\text { stiffness }\end{array}$ \\
$\begin{array}{ll}\text { Failure index } \\
\text { Bending stiffness of the } 3^{\text {rd }} \text { generation, Equation (2), should be at } \\
\text { least equal to half of the one of the } 2^{\text {nd }} \text { generation. } \\
\text { The failure index } F \text { gives the failure condition of the laminate and } \\
\text { it is determined using the Tsai-Hill criterion, Equation (6). }\end{array}$ \\
\hline
\end{tabular}


Table 9 Responses' values and their corresponding proportion factors for different design solutions

\begin{tabular}{|c|c|c|c|c|c|c|c|c|c|c|c|c|c|c|c|c|}
\hline \multirow{3}{*}{ Responses } & \multicolumn{16}{|c|}{ Selected Solutions } \\
\hline & \multicolumn{2}{|c|}{ S1 } & \multicolumn{2}{|c|}{$\mathbf{S 2}$} & \multicolumn{2}{|c|}{ S3 } & \multicolumn{2}{|c|}{ S4 } & \multicolumn{2}{|c|}{ S5 } & \multicolumn{2}{|c|}{ S6 } & \multicolumn{2}{|c|}{ S7 } & \multicolumn{2}{|c|}{ S8 } \\
\hline & $O b j$ & $p \%$ & $O b j$ & $p \%$ & $O b j$ & $p \%$ & $O b j$ & $p \%$ & $O b j$ & $p \%$ & $O b j$ & $p \%$ & $O b j$ & $p \%$ & Obj & $p \%$ \\
\hline Mass & 1.05 & 25 & 0.80 & 94 & 1.52 & 1 & 1.72 & 1 & 1.01 & 1 & 1.68 & 1 & 1.17 & 1 & 1.61 & 1 \\
\hline Material Cost & 0.83 & 20 & 0.69 & 1 & 1.69 & 1 & 1.77 & 1 & 0.56 & 94 & 2.07 & 1 & 1.78 & 1 & 1.36 & 1 \\
\hline $\begin{array}{l}\text { Torsion } \\
\text { Stiffness }\end{array}$ & 1.14 & -20 & 0.61 & -1 & 2.79 & -94 & 2.40 & -1 & 0.98 & -1 & 2.76 & 1 & 2.14 & 1 & 1.82 & 1 \\
\hline $\begin{array}{l}\text { Bending } \\
\text { Stiffness }\end{array}$ & 2.10 & -20 & 0.97 & -1 & 1.68 & -1 & 3.35 & -94 & 0.94 & -1 & 1.80 & 1 & 1.17 & 1 & 2.41 & 1 \\
\hline $\begin{array}{l}\text { Displacement } \\
\text { (front brake) }\end{array}$ & 0.91 & 5 & 2.38 & 1 & 0.65 & 1 & 0.42 & 1 & 1.25 & 1 & 0.46 & 1 & 1.16 & 1 & 0.38 & 94 \\
\hline $\begin{array}{l}\text { Displacement } \\
\text { (front impact) }\end{array}$ & 1.22 & 5 & 2.22 & 1 & 0.50 & 1 & 0.56 & 1 & 1.18 & 1 & 0.49 & 1 & 0.39 & 94 & 0.90 & 1 \\
\hline $\begin{array}{l}\text { Displacement } \\
\text { (curb strike) }\end{array}$ & 0.65 & 5 & 1.21 & 1 & 0.37 & 1 & 0.28 & 1 & 0.69 & 1 & 0.26 & 94 & 0.42 & 1 & 0.37 & 1 \\
\hline $\begin{array}{l}\text { Hill Failure } \\
\text { Index - } F\end{array}$ & 0.03 & - & 0.03 & - & 0.02 & - & 0.04 & - & 0.02 & - & 0.03 & - & 0.02 & - & 0.04 & - \\
\hline$P_{s}$ & -0.010 & & 0.0264 & & -0.9264 & & -0.9293 & & 0.0109 & & 0.0057 & & 0.0074 & & 0.0051 & \\
\hline
\end{tabular}



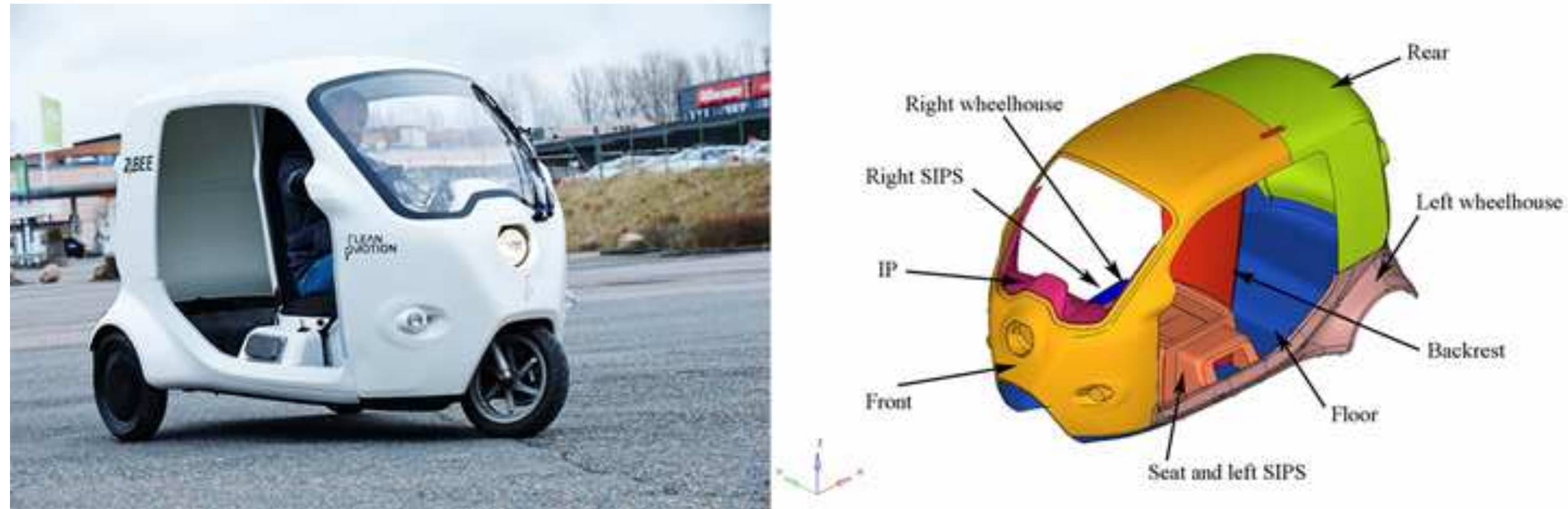
Click here to download high resolution image
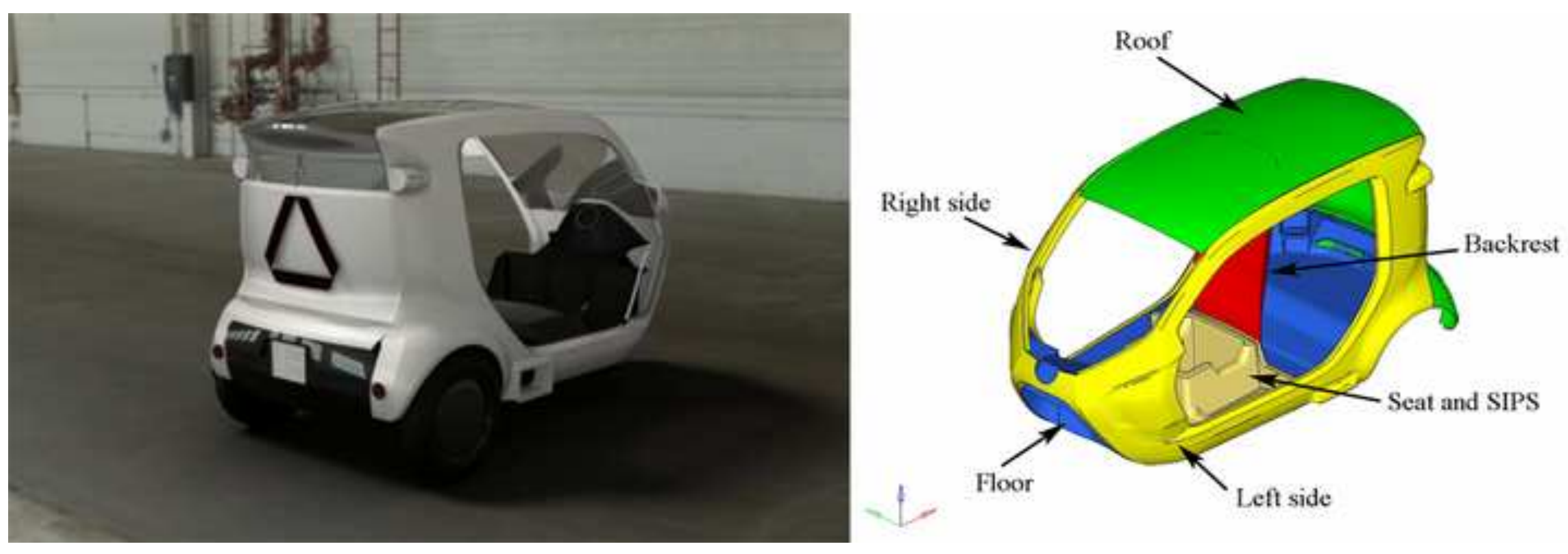
Click here to download high resolution image

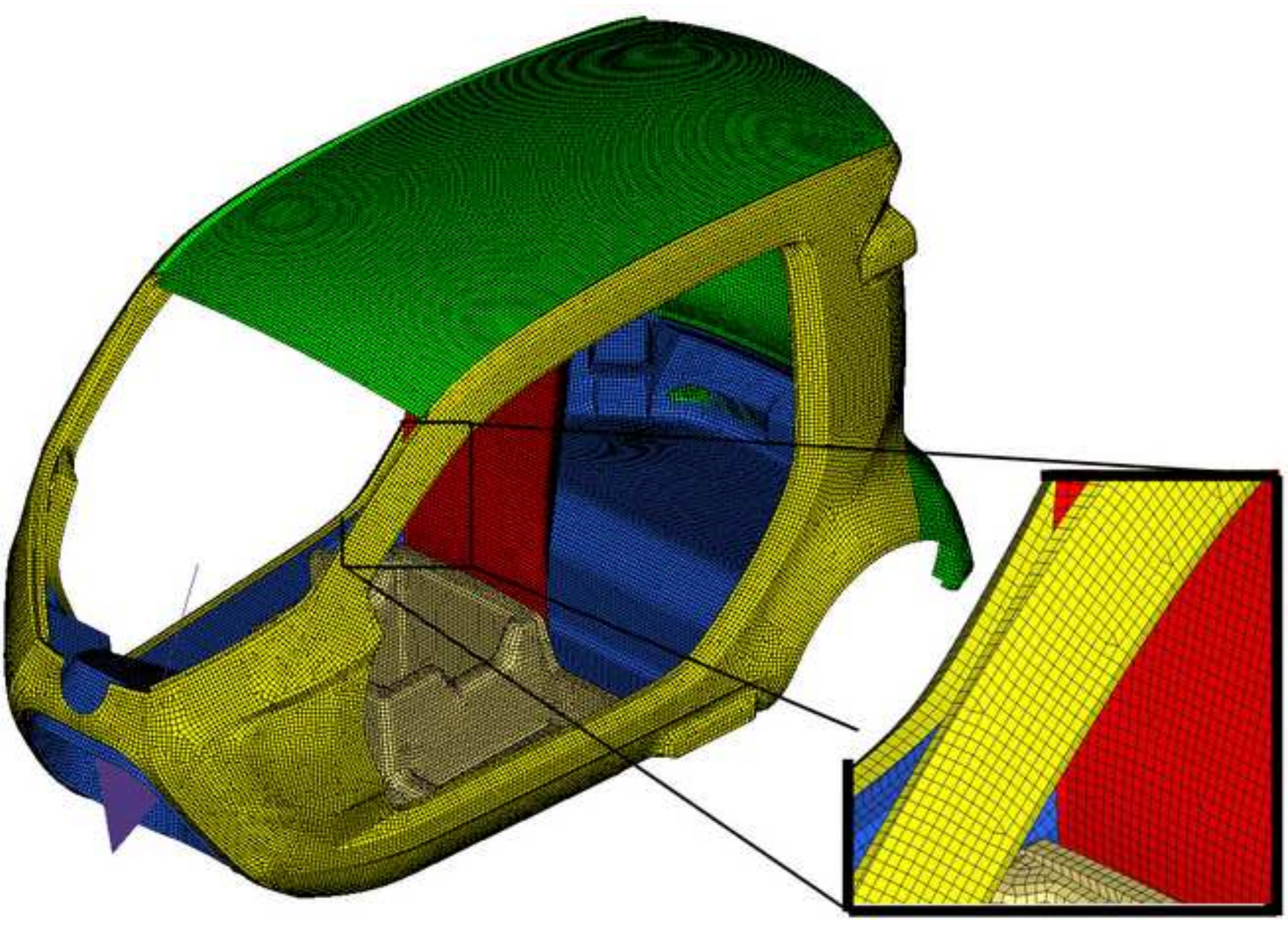


Click here to download high resolution image

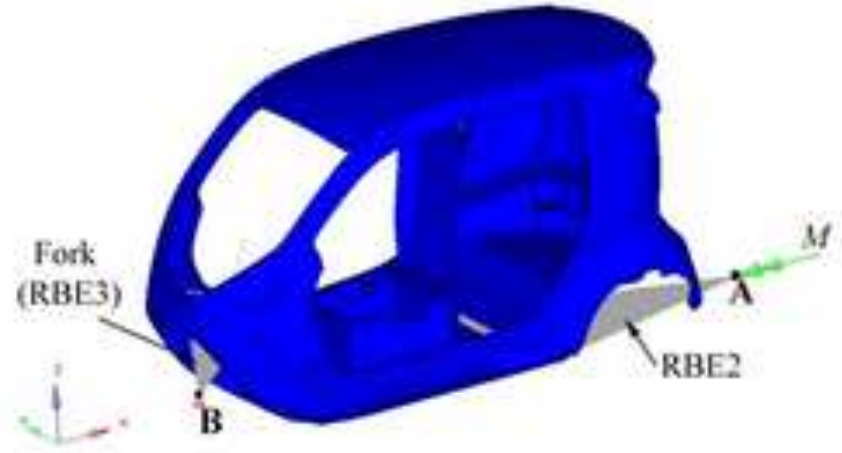

(a)

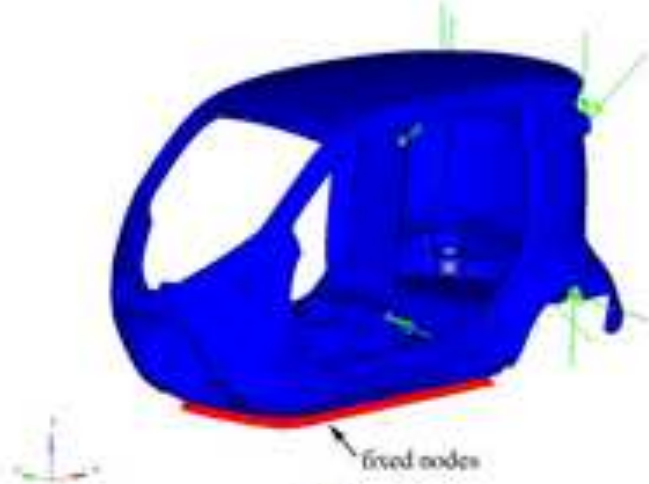

(d)

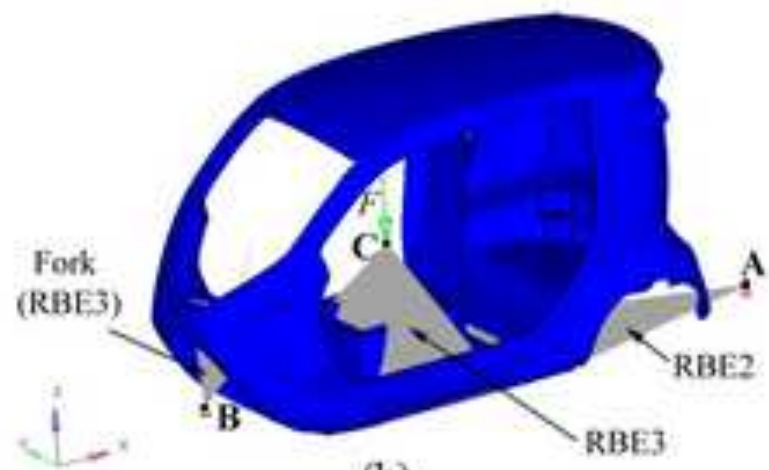

(b)

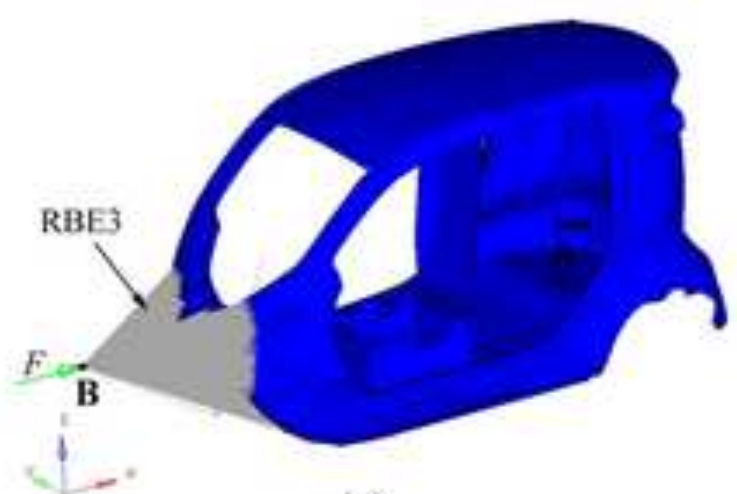

(e)
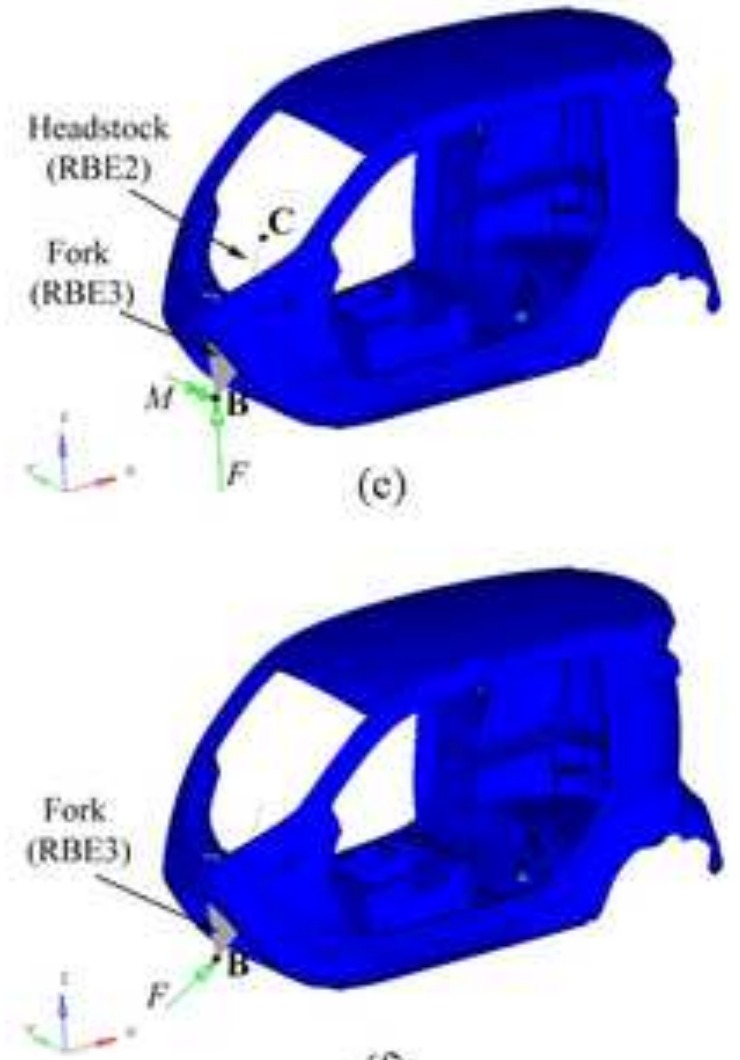

(f) 


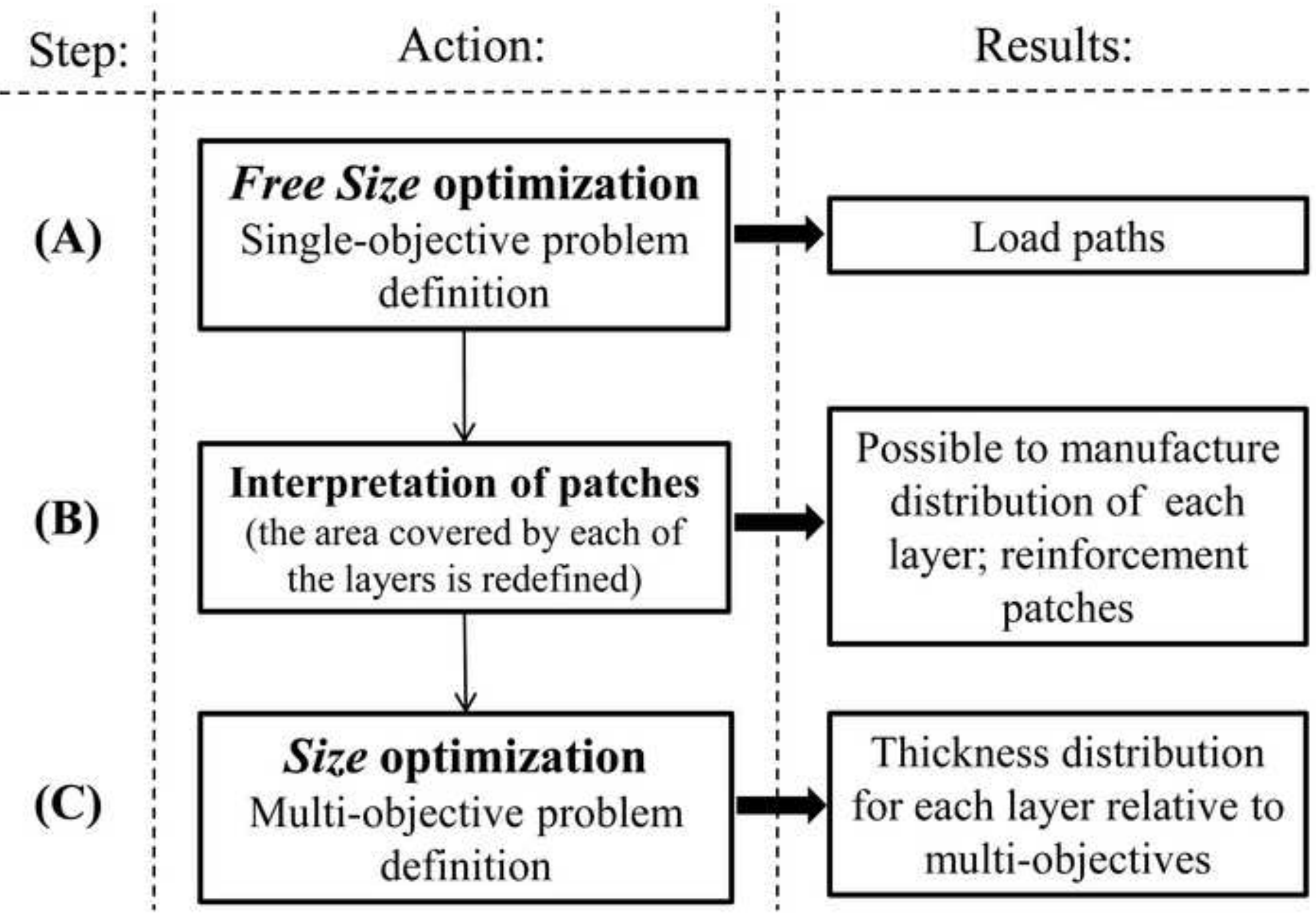




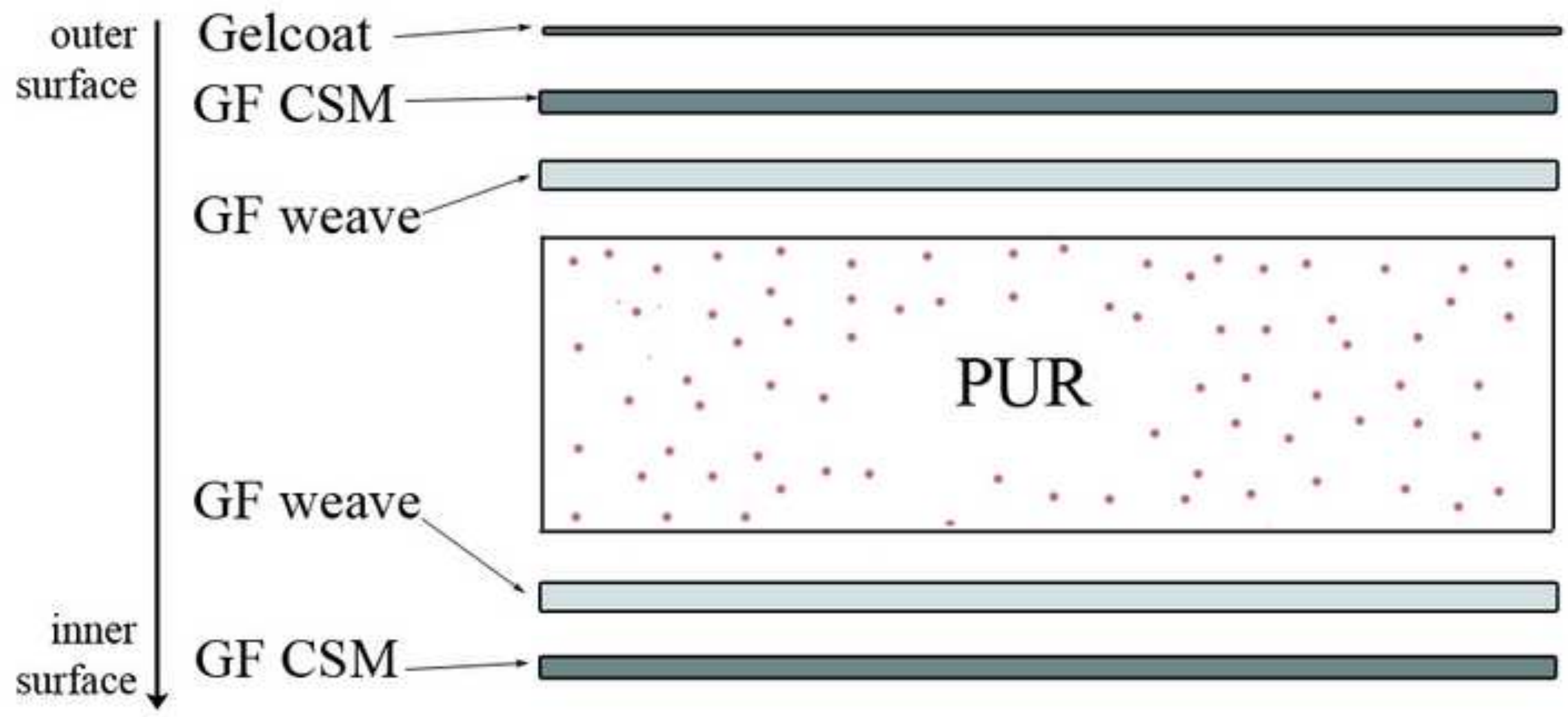


Click here to download high resolution image

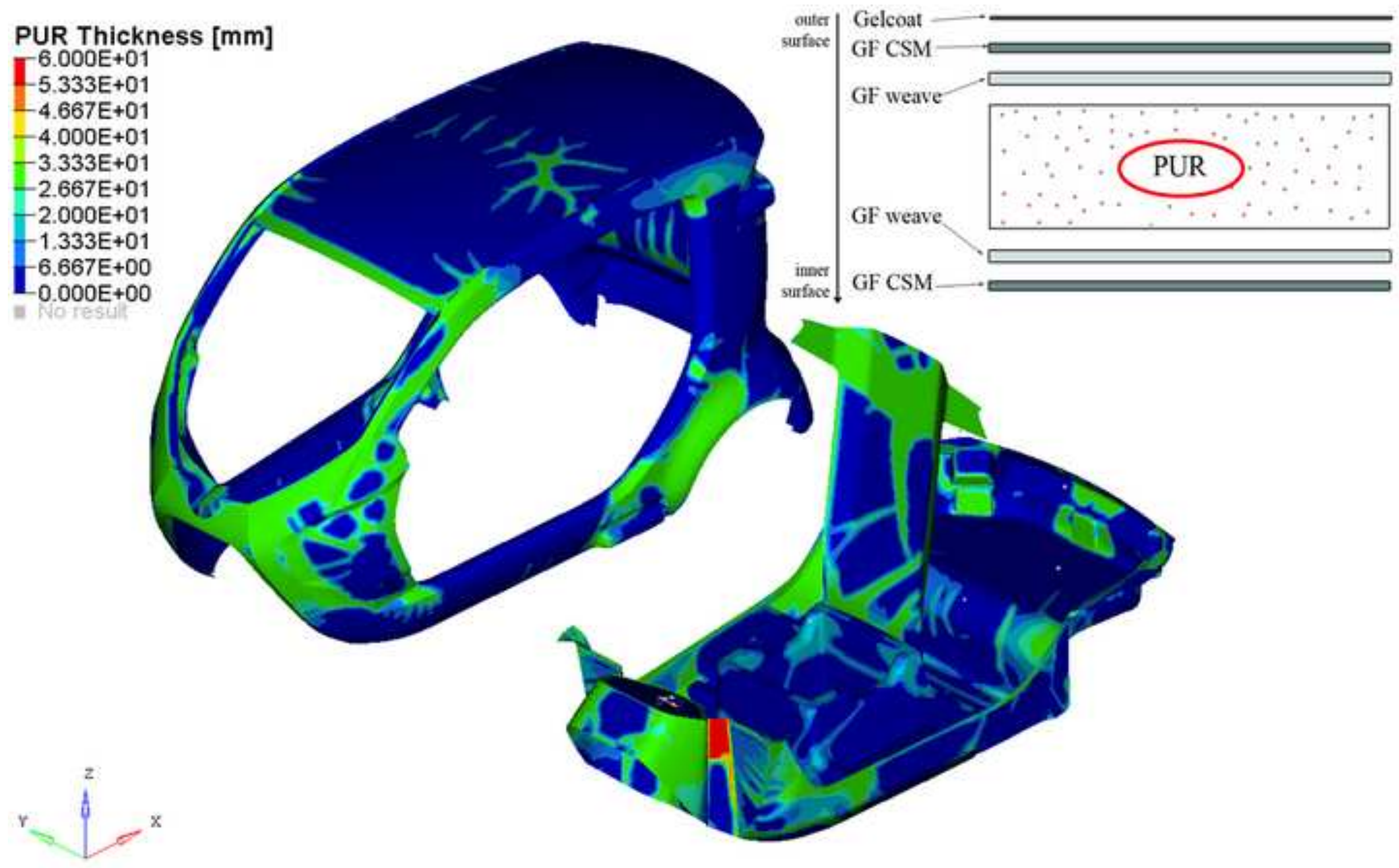


Click here to download high resolution image

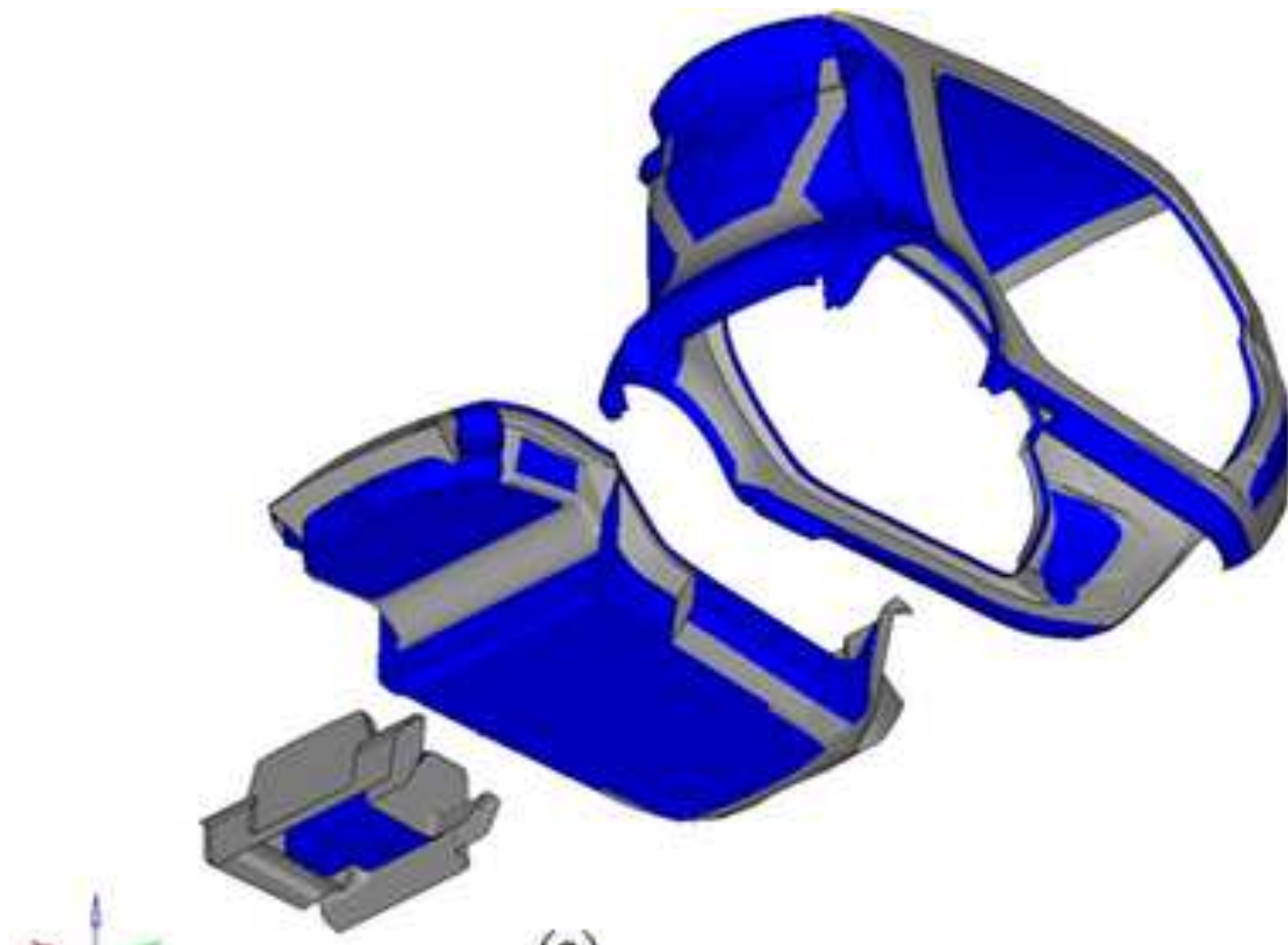

(a)

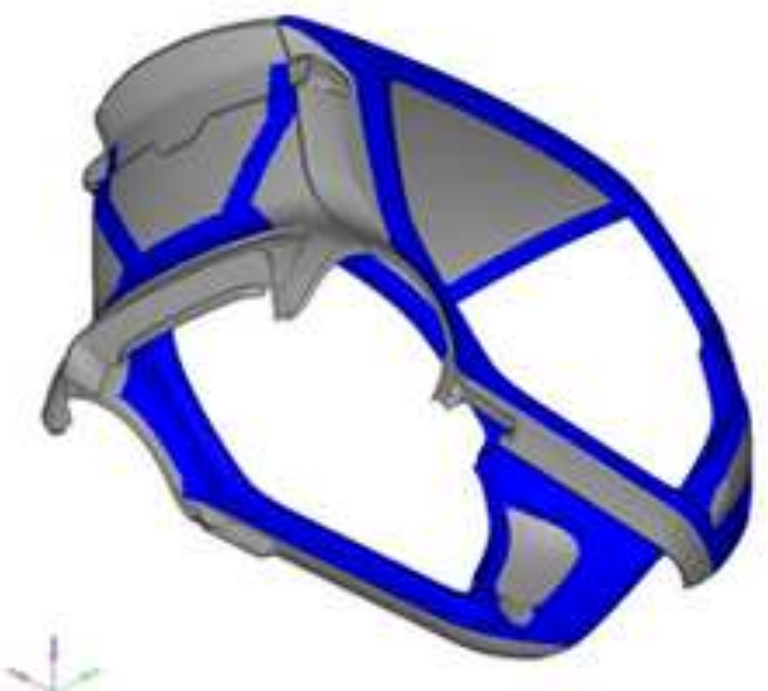

(c)

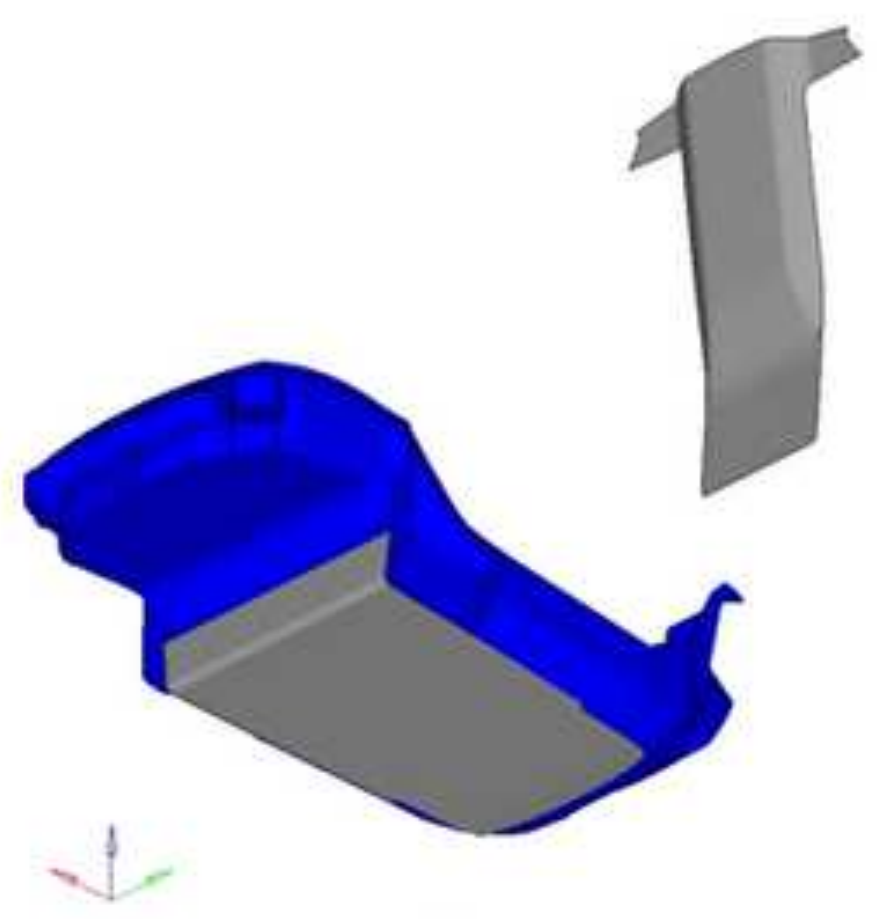

(b)

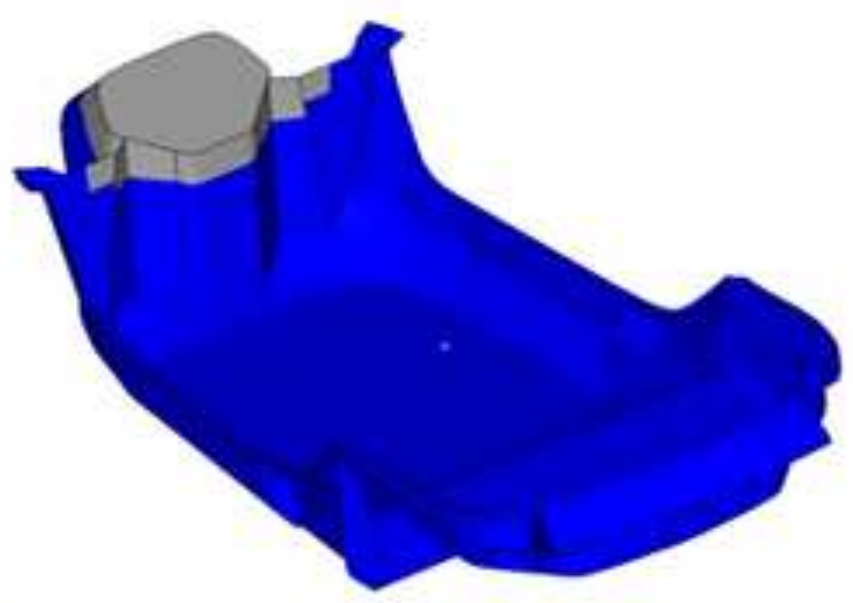

(d) 


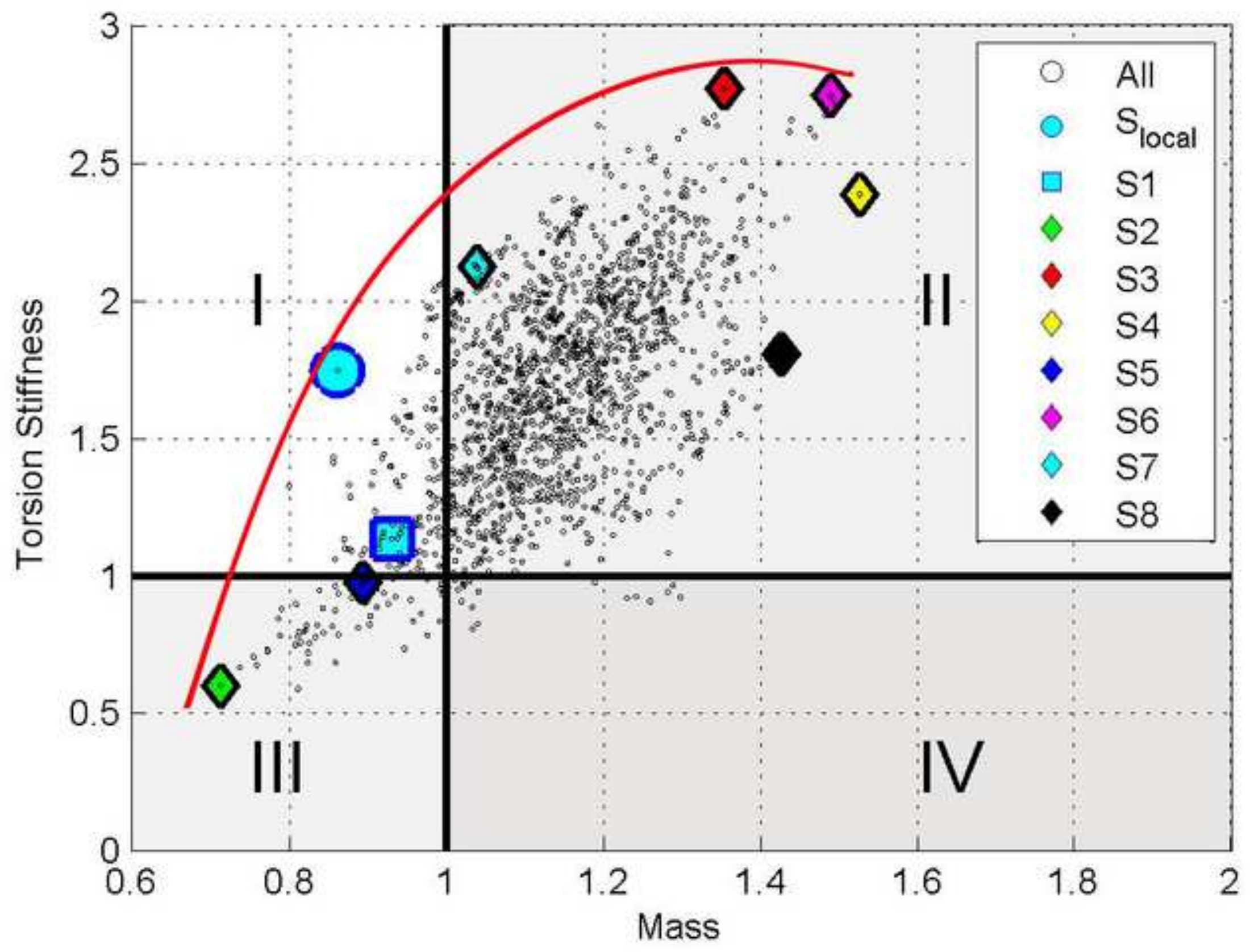




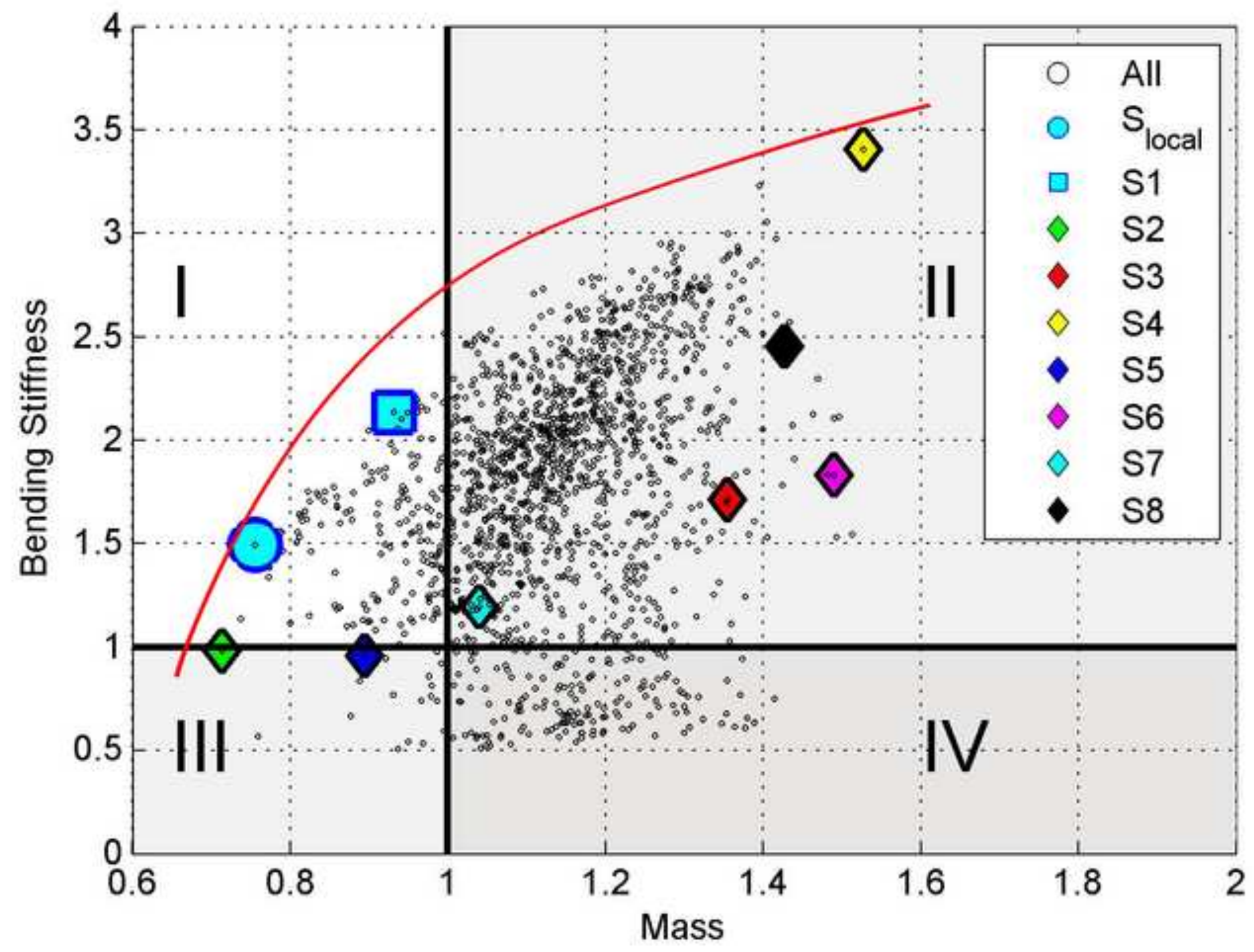




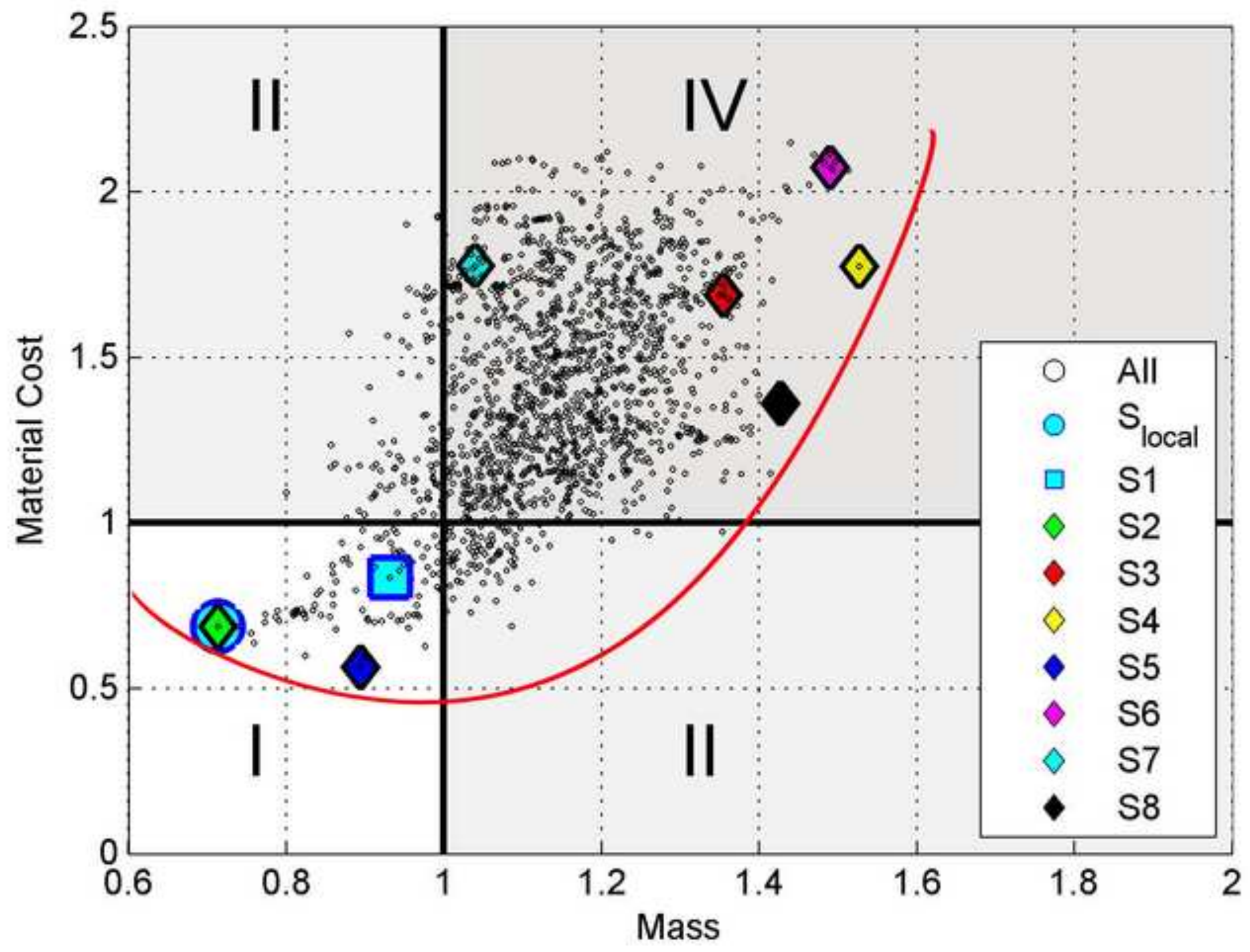


Click here to download high resolution image

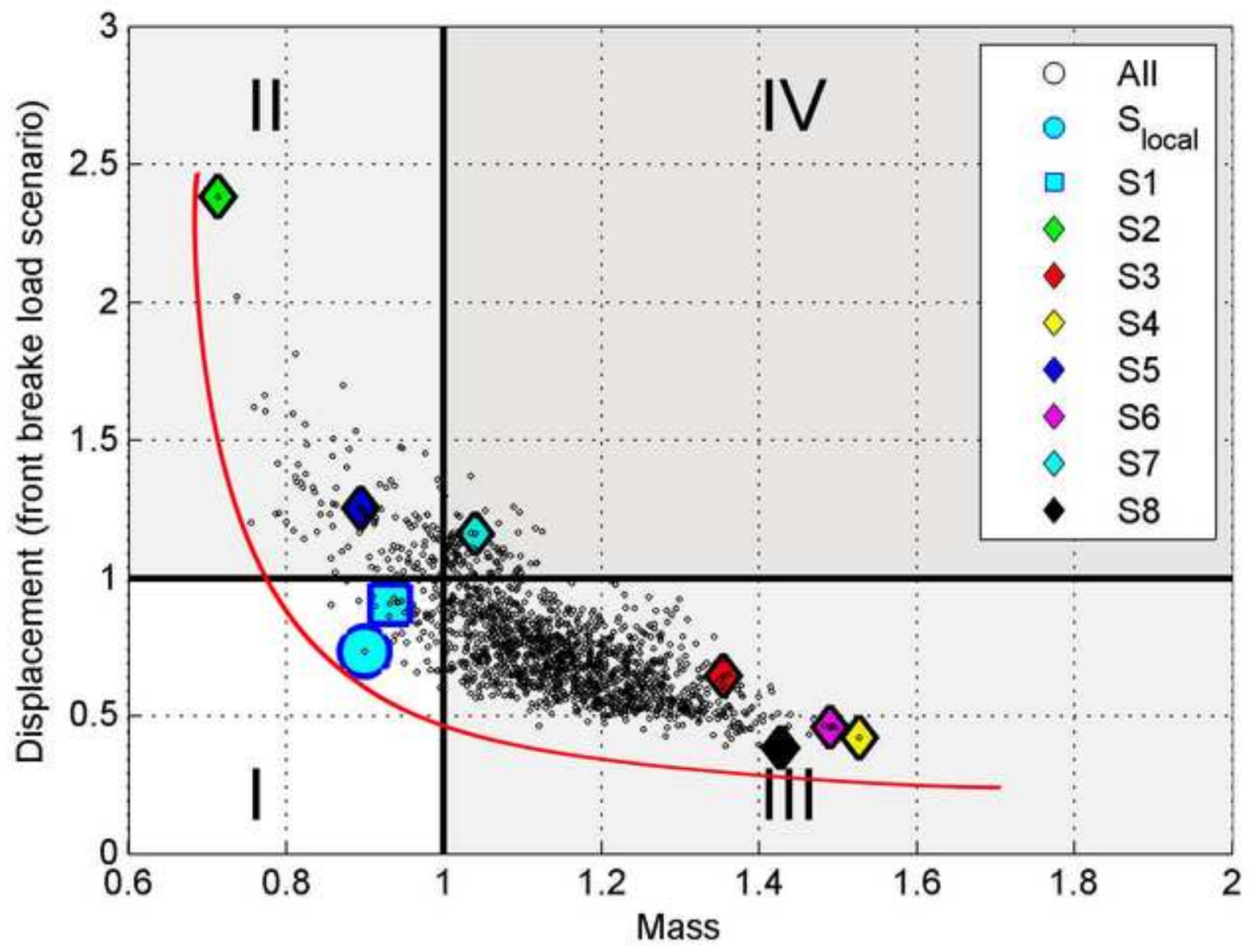




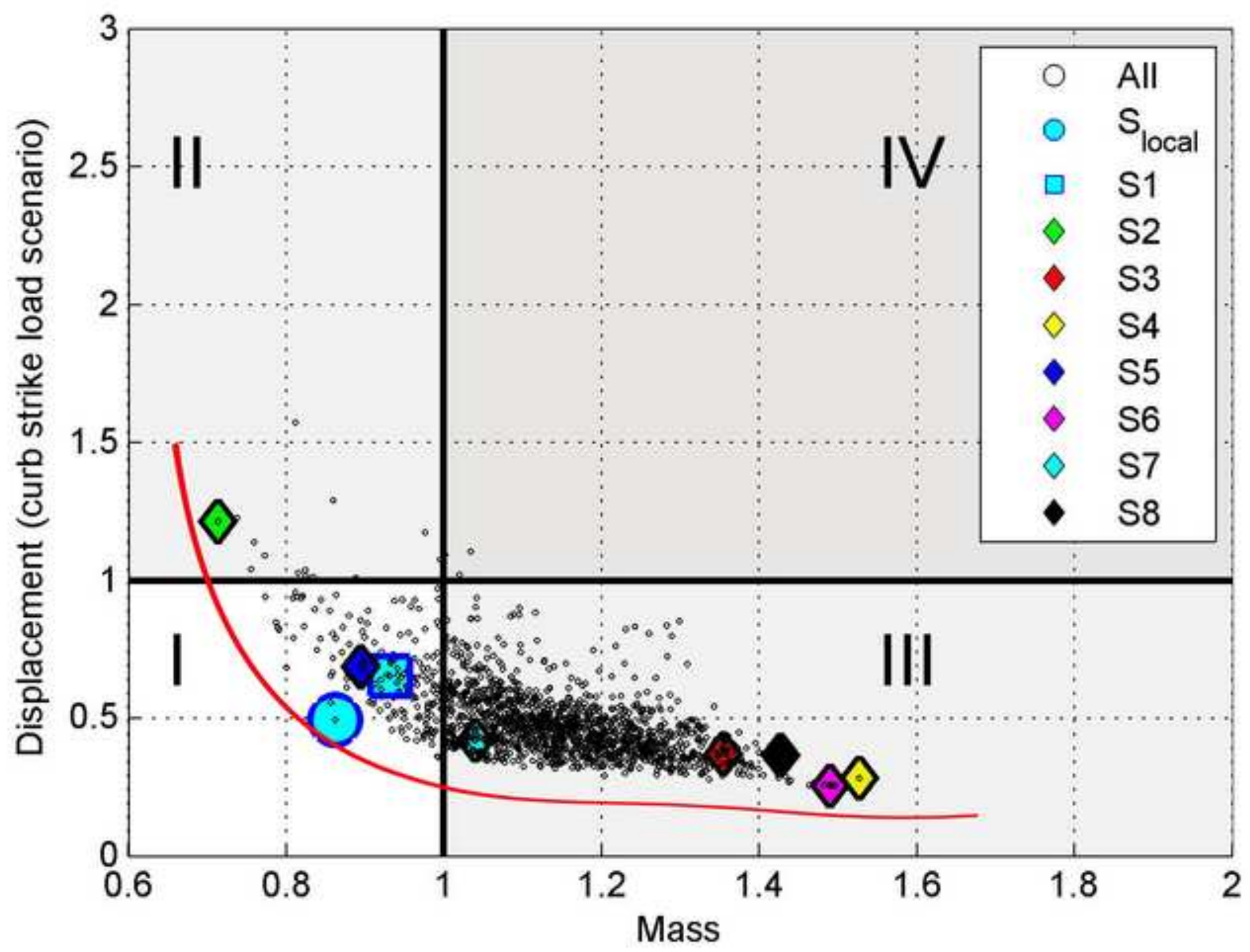




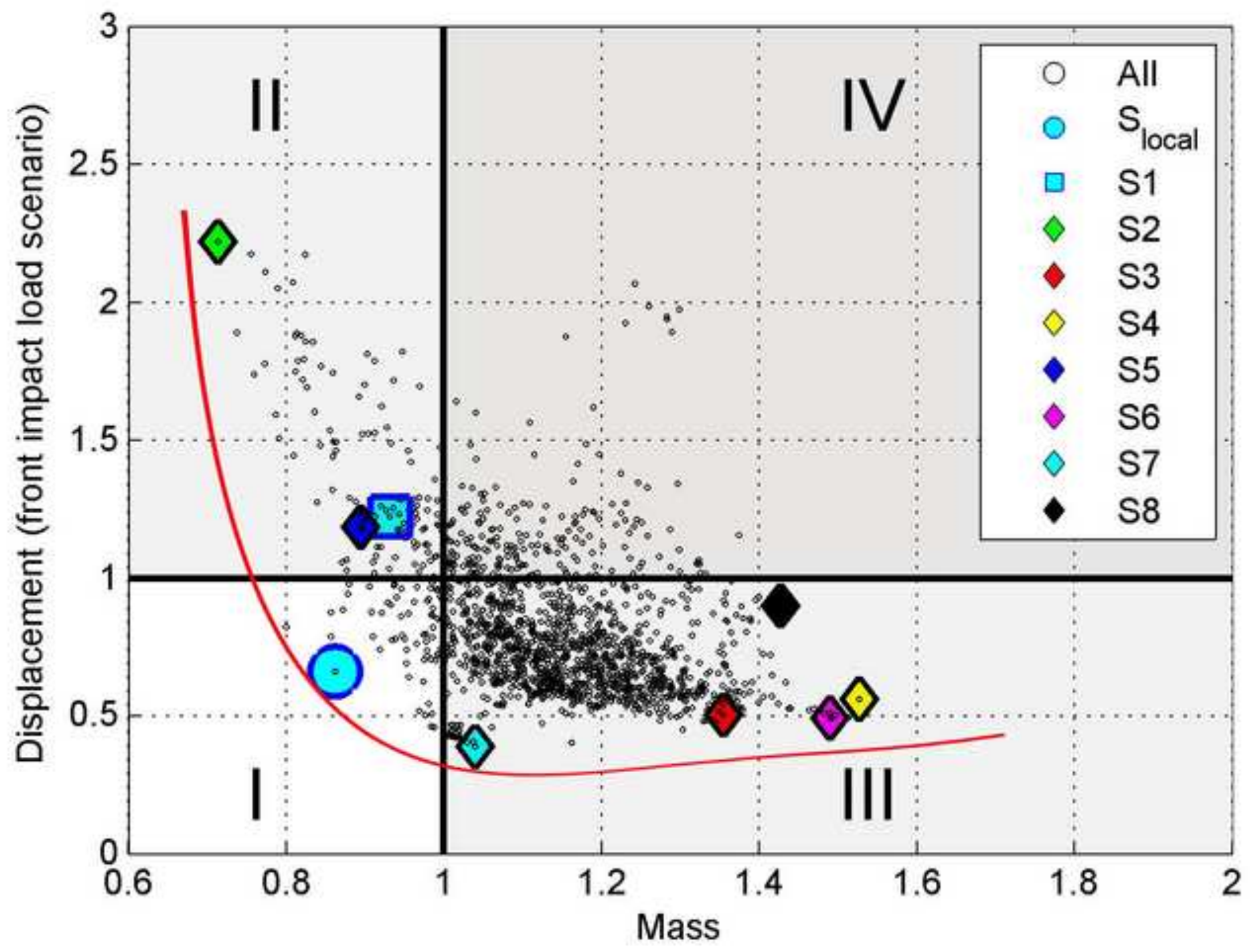




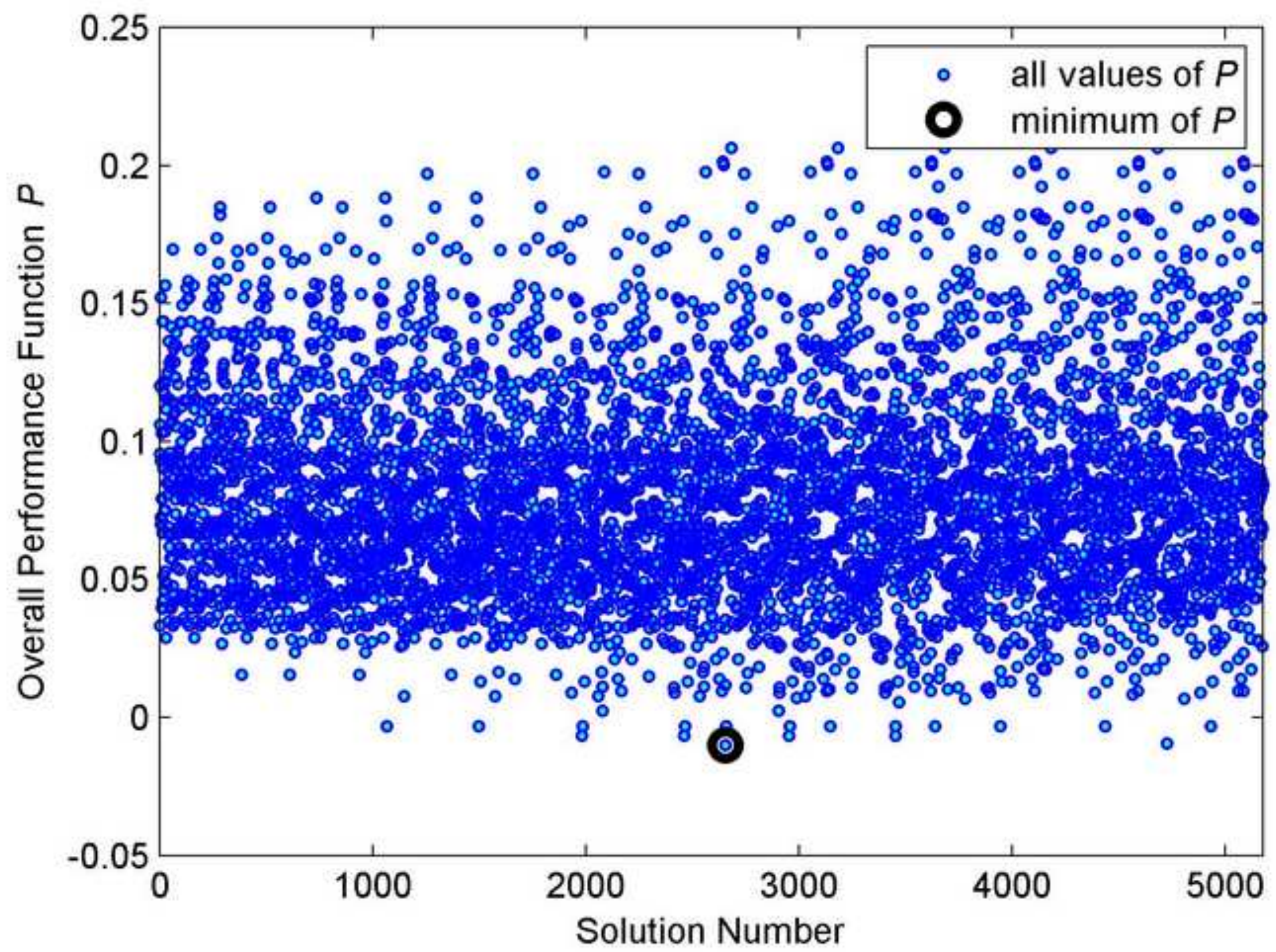




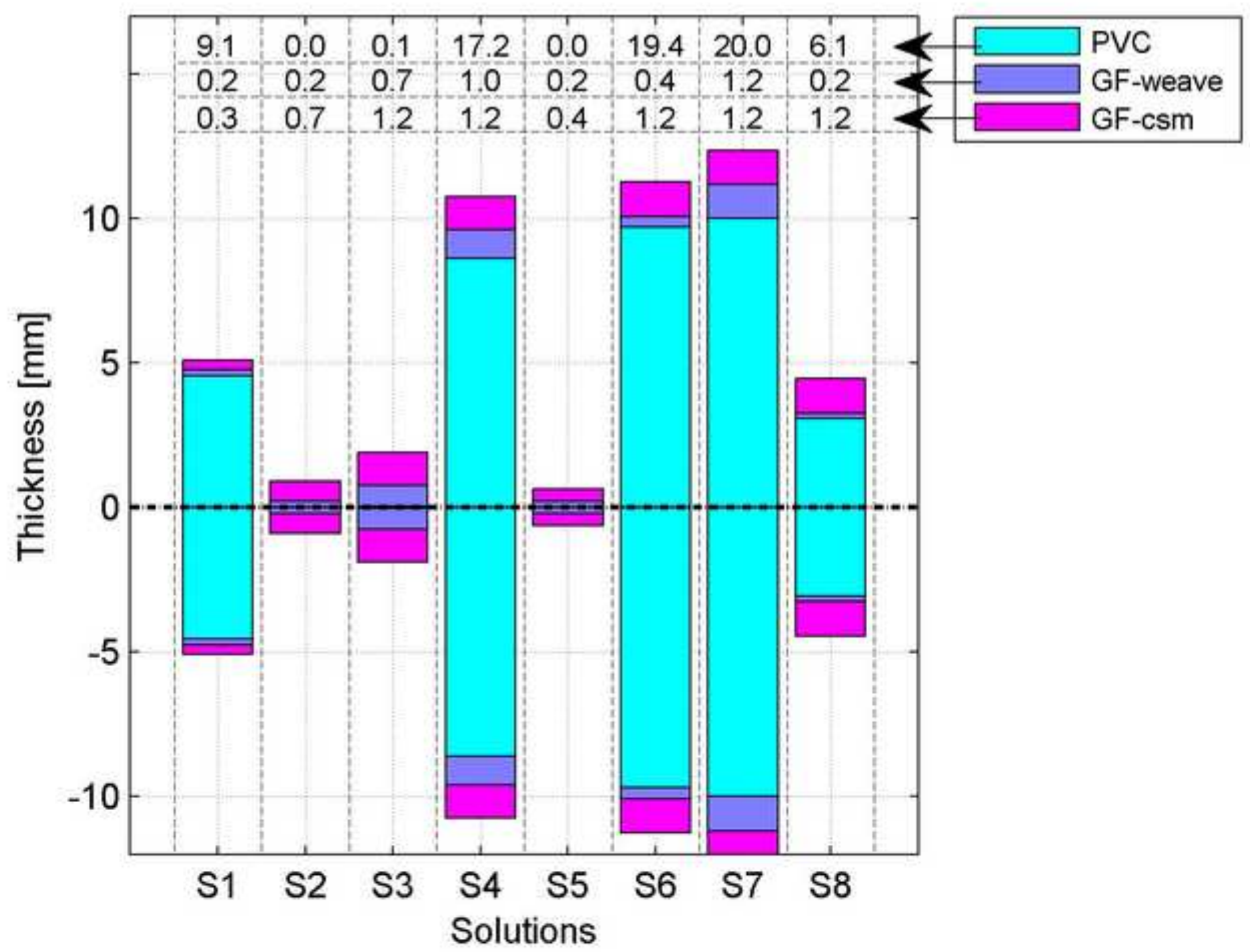




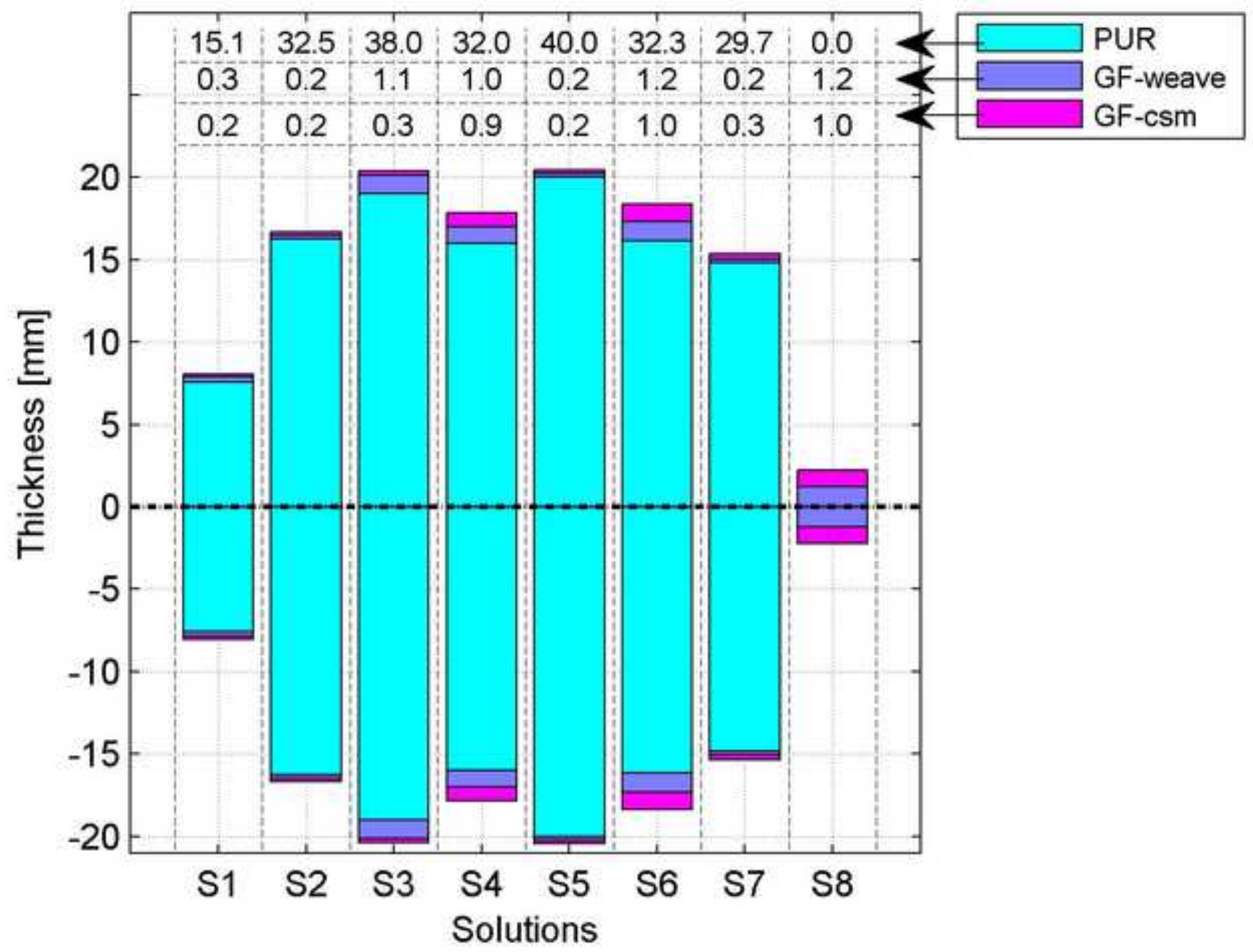

